Est Ag 39 (2004) 33-78

\title{
Los catecismos de Claret
}

El punto de partida para profundizar en la actividad de Antonio $\mathrm{M}^{\mathrm{a}}$ Claret como autor de catecismos, es que hay un substrato de catequista fogueado en la práctica pastoral diaria que no debe ser despreciado. A Claret habría que situarle, en primer lugar, como catequista, más que como catequeta, de acuerdo con la terminología actual.

Él también escribió y reflexionó sobre la catequesis de su época y sobre algunos de los problemas más acuciantes. Esta segunda faceta no empaña la fuerza abrumadora de la primera dimensión: la del hombre que se dedicó a la tarea pastoral directa, y tomó conciencia rápida de que, frente a la extendida ignorancia religiosa, se imponía, por encima de todo, una labor de formación consistente en difundir el libro del catecismo; en él se incluye lo que es necesario saber para que el cristiano viva bien formado. Según los patrones del siglo XIX, la difusión del catecismo apuntaba a que fuera aprendido de memoria y, hasta donde llegaba la claridad del texto y la capacidad de cada sujeto, pudiera ser también entendido.

Una preocupación preferente de su época fue conseguir la mayor exactitud posible en la presentación de la fe, de manera que ésta resultara aquilatada y segura, sin resquicios, aunque se sacrificara hasta cierto punto la comprensión. La fe bien expresada y bien aprendida y repetida, era garantía de una óptima formación religiosa.

No es posible suponer que tanto Claret como sus contemporáneos se conformaron con un cristianismo de meros repetidores. Pero dado el abultado índice de analfabetismo (resultado del bajo nivel de escolarización), y, dadas las acometidas agresivas que sufría el catolicismo, se consolidó la tendencia de ofrecer una doctrina que garantizase la seguridad. Ésta corría a cargo de especialistas, que recogían expresiones del pasado, e incorporaban fórmulas que dejaran a salvo la certeza de lo escrito, aunque no fuera bien comprendido. Importaba sobre todo que estuviera bien expresado; lo otro resultaba secundario en el ambiente eclesial del XIX. Por lo tanto, que se entendiese lo que se quería decir no dejaba de ser privilegio de unos pocos, que disponían de mayor formación; la mayoría se limitaba a repetir las 
expresiones que les habían suministrado, con un rancio sabor tradicional; tales expresiones eran intocables.

Claret vivió de lleno en esta corriente, que venía de tiempo atrás; los vaivenes ideológicos del siglo XIX contribuyeron a fortalecerla, de manera que la Iglesia sufrió un fuerte repliegue de reafirmación en sus ideas «de siempre»; la postura destacada no fue el diálogo con el mundo, sino el rechazo y huida de ese mundo que se manifestaba hostil y agresivo. No es fácil precisar quién resultó más intolerante, si la Iglesia o el mundo que la rodeaba.

En el terreno de la catequesis, Claret se esforzó por conseguir una mayor difusión de la doctrina cristiana, especialmente entre aquéllos a los que no se llegaba por los medios habituales: los no escolarizados (por razón de clase social y por condición económica), o los habitualmente distantes de la acción eclesial (labradores, pastores, arrieros,...), y los que militaban en organizaciones adversas a la Iglesia (ilustrados, liberales, socialistas,...). No todos se encontraban en la misma situación, aunque todos compartían una formación religiosa escasa.

Como su deseo juvenil y su fogoso temperamento no le permitían a Claret permanecer tranquilo ante un clima semejante, su actividad se centró en la difusión de la enseñanza del catecismo (entre otras tareas): empezó con la difusión de los catecismos más comunes, y siguió con la elaboración y edición de nuevos textos. Es posible diferenciar tres fases en su preocupación por la catequesis:

$1^{\mathrm{a}}$, la de difusor de los catecismos usuales;

$2^{\text {a }}$, la de escritor de varios textos de catecismo;

$3^{\mathrm{a}}$, la de editor de los materiales suyos (junto a otros ajenos).

Se podría señalar para la tercera la fecha de 1848 , con la puesta en marcha de la Librería Religiosa, aunque antes editó muchos materiales impresos en diversos lugares. Para la segunda etapa se podría partir de 1846 , fecha de su catecismo primero, aunque otros escritos pastorales o piadosos incluían un cierto tinte catequético. Para la primera etapa había que remontarse a su ordenación sacerdotal en 1835, pero los años anteriores había manifestado un sincero deseo de extender la fe cristiana. La diferenciación es más útil para sistematizar su pensamiento y acotar el estudio, que para encasillar una vida. Más adelante, con una visión más amplia, surgirá el pensamiento casi obsesivo de llegar a la unificación del catecismo, que puede ser contemplada como cuarta etapa, diferenciada de las anteriores, y en la que actúa más como catequeta que como catequista. 
Si resalto la primera etapa es porque su empeño como misionero itinerante le llevó una y otra vez, en diferentes lugares, a ponerse en contacto con personas habitualmente alejadas de la acción pastoral directa, pero que de forma excepcional acudían a la misión popular; en ella Claret comprobó el escaso nivel de preparación e intentó elevarlo insistiendo en la necesidad de conocer la doctrina cristiana. El hecho de que repitiese los mismos sermones y explicaciones una y otra vez en diversos lugares, muestra el objeto de su preocupación central y sus desvelos. Sus mismas palabras, cuando da razón de su actividad misionera, lo muestran:

«El Catecismo de los niños.- La primera cosa que procuraba era la instrucción de los niños en la Doctrina cristiana, ya por afición que siempre he tenido a esta clase de enseñanza, ya también porque conocía que es lo más principal, por ser el Catecismo fundamento de este edificio de la instrucción religiosa y moral. Además los niños lo aprenden fácilmente, se les queda más impreso, se les preserva del error, del vicio y de la ignorancia y se les forma en la virtud muy fácilmente por ser más dóciles que los adultos. En los niños sólo hay el trabajo de plantar, y en los adultos el de arrancar y plantar. Hay además otra ventaja, que con los niños se conquista a los grandes, y con los hijos a los padres, porque los hijos son pedazos del corazón de los padres. Además, dándoles en premio de su asistencia y aplicación alguna estampita, los padres y adultos las leen en casa por curiosidad, y no pocas veces se convierten como lo sé por experiencia».

«El Catecismo a los mayores es el medio que he conocido hacía más fruto. Con él se les sacaba de la ignorancia, que es mayor de lo que se puede figurar, aun entre aquellas personas que oyen sermones con frecuencia, porque los predicadores suponen un auditorio instruido, y cabalmente esta instrucción es la que falta por lo común entre los católicos. Y además se les instruye en sus respectivas obligaciones y en el modo de cumplirlas»1.

Esta condición inicial de catequista llevó a Claret a enseñar y explicar el contenido de la doctrina cristiana, a niños y a adultos, y los esfuerzos repetidos en esta actividad, por idénticos y habituales, no han dejado tanta constancia como el ser autor de catecismos, más fácil de comprobar. Pero conviene recordar que de lo uno se pasa a lo otro.

En efecto, la difusión de la doctrina cristiana, en las misiones populares, le hizo tomar conciencia de la extendida ignorancia religiosa, y de la necesidad de atajarla. Su extensa actividad literaria no podía dejar de lado la catequesis, que constituía una de sus preocupaciones centrales. Por consi-

1. A. Claret, Autobiografía, en J. Viñas, (ed.), San Antonio María Claret. Escritos autográficos y espirituales, Madrid, BAC, 1959, 270-271 y 273. 
guiente el paso de la primera actividad difusora y de explicación del catecismo, a la segunda, de tomar la pluma para escribir catecismos entre otras obras es totalmente lógico. Más adelante, a la vista de las dificultades propias de la edición, de los tiempos de espera impuestos por las imprentas, de las repercusiones económicas, se decidió por editar sus obras.

Considerando a Claret como autor de catecismos, pasó insensiblemente de catequista a catequeta: al principio se conformó con ediciones sencillas, casi rutinarias con respecto a lo que venía siendo común en su entorno; después, a través de la reflexión, comenzó a perfilar unos textos de catecismo, pensados, suficientemente madurados y elaborados: lo propio de un catequeta.

Ahora bien, lo difícil es precisar cuántos catecismos escribió Antonio $\mathrm{M}^{\mathrm{a}}$ Claret. Es patente que no basta con poner al frente de un escrito la palabra «catecismo», para aceptar que lo sea. De ahí que el concepto más ajustado de catecismo incluya o excluya algunos escritos de Claret, entendiendo como tal los escritos que contienen una explicación completa de lo esencial de la doctrina cristiana. Al examinar con esta perspectiva sus escritos, aparecen puntos de vista diversos. Así, J. M. Viñas ${ }^{2}$ indica las siguientes obras:

1. Para que Dios sea conocido: Los Catecismos... [sin fecha]

2. Catecismo de los principales deberes de un militar cristiano, Barcelona, Plá, 1846.

3. Catecismo menor, Barcelona, Plá, 1847.

4. Catecisme de la Doctrina Cristiana explicat y adaptat..., Barcelona, Plá, 1848.

5. Compendi o breu explicació de la Doctrina Cristiana..., Barcelona, Plá, 1848.

6. Catecismo de la Doctrina Cristiana, explicado y adaptado..., Barcelona, Plá, $1849,2^{a}$ ed.

7. Manná del cristiá, Vich, Trullás, 1850.

8. Doctrina Cristiana (Carta sobre la Hermandad), Santiago de Cuba, Espinal, 1851.

9. Maná del cristiano, Barcelona, Librería Religiosa, 1857.

10. Compendio o breve explicación de la Doctrina Cristiana, Barcelona, Librería Religiosa, 1864.

11. Catecisme de la Doctrina Cristiana, escrit per..., Barcelona, Librería Religiosa, 1867.

12. Unidad del catecismo, Barcelona, Librería Religiosa, $1867^{3}$.

2. J. M. VIÑAs (ed.), o. c., 273, nota 116.

3. J. M. VIÑAs, o. c., 132-137. 
Tal lista es confusa, mezcla de ediciones castellanas y catalanas, y resulta incompleta. Yo mismo traté de completarla y perfeccionarla 4 . En cambio, una información más exacta, con algunos detalles (títulos completos), eliminando una obra y añadiendo un ejemplar diverso, no consignado antes, me ha permitido establecer la siguiente lista:

1. Catecismo de los principales deberes de un militar cristiano, Barcelona, Plá, 1846.

2. Catecisme menor que per la ensenyansa dels noys y noyas luego que saben parlar ha escrito lo $R$. D... y han adoptat las societats de la Doctrina Cristiana del Principat de Catalunya, Barcelona, Plá, 1847.

2 bis. Primer catecismo que se enseñará a los niños desde que empiecen a hablar, Barcelona, Lib. Religiosa, $1875^{5}$.

3. Catecismo brevísimo que solamente contiene lo que indispensablemente ha de saber todo cristiano, compuesto por..., Las Palmas, J. B. Ortega, 1848.

4. Compendi o breu explicació de la Doctrina Cristiana, en forma de dialogo entre pare y fill, que per la instrucció de sos feligresos compongué lo Dr. Francesch Matheu y Smandía, prebere y rector que fou de la iglesia de sant Pere de Bigas y de sant Baldiri de Llobregat, bisbat de Barcelona, aumentat y metodisat per lo Rt. Anton Claret, Barcelona, Her. de la V. Plá, 1848 (versión catalana).

4 bis. Compendio o breve explicación de la Doctrina Cristiana, Barcelona, Librería Pau Riera, 1859 (versión castellana).

5. Catecisme de la doctrina cristiana explicat y adaptat a la capacitat dels noys y noyas y adornat ab moltas estampas, Barcelona, Plá, 1848 (versión catalana).

5 bis. Catecismo de la Doctrina Cristiana, explicado y adaptado a la capacidad de los niños y adornado con muchas láminas, Barcelona, Plá, 1848 (versión castellana).

6. Catecisme de la Doctrina Cristiana, escrit per..., Barcelona, Librería Religiosa, 1867 (versión catalana).

4. L. Resines, La catequesis en España. Historia y textos, Madrid, BAC, 1997, 575.

5. La obra consta, tras el prólogo y una advertencia, en la edición $15^{\mathrm{a}}$ del Catecismo de la doctrina cristiana explicado y adaptado a la capacidad de los niños y adornado con muchas láminas; data de 1862. Figura con el título de Primer catecismo que se enseñará a los niños desde que empiezan a hablar hasta los siete años. La fecha de 1875 resulta sólo indicativa de alguna edición castellana, como texto autónomo; en versión catalana circulaba desde 1847 . 
6 bis. Catecismo de la Doctrina Cristiana escrito por el Excmo. e Ilmo. Sr. Antonio $M^{a}$ Claret, arzobispo de Trajanópolis, in part[ibus]. infid[elium]., y dedicado a la Inmaculada Concepción de María Santísima, patrona de las Españas, Madrid, 1866.

Son seis catecismos distintos, de los cuales cuatro disponen de versión castellana y catalana. Resulta más complicado saber siempre con absoluta certeza, en cada caso, si apareció primero una u otra versión; tampoco he podido disponer de datos para reconstruir la historia de cada una de las obras y sus versiones, con la fecha de las sucesivas ediciones. Sí es posible asegurar con certeza que las ediciones castellanas superaron en número a las catalanas, por la mayor difusión de una lengua respecto de la otra. $\mathrm{He}$ eliminado de la lista la obra titulada Manná del cristiá (versión catalana) o Maná del cristiano (versión castellana): antes no había tenido ocasión de examinarla, y me guié por el subtítulo que figura en la referencia de J. M. Viñas. Sin embargo, he podido examinar un ejemplar, y lo cierto es que no tiene contenido catequético alguno, sino que se trata de un compendio de prácticas de piedad 6 , pero no es un catecismo.

La primera obra Catecismo de los principales deberes de un militar cristiano no constituye propiamente un catecismo; se trata de una reflexión, que llama «catecismo», por estar redactada en preguntas y respuestas. A través de ellas desgrana las obligaciones profesionales, y la forma de compatibilizar la milicia con el comportamiento cristiano.

\section{CATECISME MENOR... (BARCELONA, 1847)}

El Catecisme menor que per la ensenyansa dels noys y noyas luego que saben parlar ha escrito lo $R$. D... y han adoptat las societats de la Doctrina Cristiana del Principat de Catalunya (en versión catalana) o Primer catecismo que se enseñará a los niños desde que empiecen a hablar (en versión castellana) es un breve escrito (al menos en la versión que conozco, de 1875) que responde al título, pues se trata de unas nociones elementales, nucleares, para que los niños tengan noticia de los aspectos básicos de la fe.

6. A. M. Claret, Maná del cristiano, arreglado por el venerable Padre..., y considerablemente aumentado por los Misioneros de dicha congregación, Madrid, Ed. del Corazón de María, 1928, 26 a ed. La obra contiene: Regla de vida, ejercicios de piedad, confesión, comunión, modo de oír la misa, trisagio, triduo al Sgdo. Corazón, rosario y letanías, via crucis, método de meditación, retiro espiritual, devoción al Corazón de María, siete dolores y gozos de S. José, novena a S. Francisco Javier, bula de Cruzada y cánticos sagrados. 
Tiene 47 preguntas, que se atienen a lo fundamental de la fe (aunque se puede dudar sobre su oportunidad de algunas, como las que insisten en la devoción a la Virgen); están destinadas a que fueran aprendidas por los niños pequeños, antes de emprender un aprendizaje sistemático, propiamente dicho. Con ellas ya disponían de una referencia previamente aprendida a la que remitir. Entre las preguntas, incluye los formularios del credo, padrenuestro, avemaría, salve, mandamientos de Dios, mandamientos de la Iglesia, sacramentos, confesión general, y acto de contrición.

Tengo conocimiento de la edición catalana de 1847; pero carezco de referencia de cuál pudo ser la fecha de la edición castellana más antigua. Sin embargo, cuando Claret incorporó nuevas preguntas en el Catecismo explicado, en 1848, echó mano de unas cuantas preguntas que figuraban en este elemental escrito. Es decir, reaprovechaba todo, y, con un criterio no pedagógico, las mismas preguntas elementales servían para los niños que sólo sabían hablar, y aparecían en un texto amplio, para chicos de más edad.

Volvió a utilizarlo cuando compuso el Catecismo de la doctrina cristiana, de dos formas: una como apéndice o síntesis del mismo 7 ; la otra, señalando las preguntas con doble asterisco, para indicar que son las más importantes y necesarias.

\section{El Catecismo brevísimo... (Las Palmas, 1848)}

Existen profundas similitudes internas entre las tres obras siguientes:

Catecismo brevísimo que solamente contiene lo que indispensablemente ha de saber todo cristiano, compuesto por..., Las Palmas, J. B. Ortega, 1848. Compendi o breu explicació de la Doctrina Cristiana, en forma de dialogo entre pare y fill, que per la instrucció de sos feligresos compongué lo Dr. Francesch Matheu y Smandía, (...) aumentat y metodisat per lo Rt. Anton Claret, Barcelona, Her. de la V. Plá, 1848 (versión catalana), y su paralelo Compendio o breve explicación de la Doctrina Cristiana, Barcelona, Librería Pau Riera, 1859 (versión castellana);

Catecisme de la doctrina cristiana explicat y adaptat a la capacitat dels noys y noyas y adornat ab moltas estampas, Barcelona, Her. de la V. Plá, 1848 (versión catalana), y su paralelo Catecismo de la Doctrina Cristiana, explicado y adaptado a la capacidad de los niños y adornado con muchas láminas, Barcelona, Her. de la V. Plá, 1848 (versión castellana).

7. Aparecen con el título de «Preguntas que se han de hacer a los niños de poca edad y a los adultos ignorantes». 
Discrepo del criterio de Jesús Bermejo, al proporcionarme copia del Catecismo brevísimo, pues manifiesta que «el Catecismo de Canarias es diferente [del Compendio] y tiene carácter de novedad $»$. He comparado estos tres catecismos de Claret, y he llegado a la conclusión de que la diferencia y la novedad no es tanta, como a primera vista podría parecer. Más aún, con arreglo a la indicación que Claret hizo en el título de su Compendio, y que consta asimismo en el prólogo del Catecismo explicado, se fundó en el texto de Francesch Matheu, pues «entre los muchos catecismos que he visto y mirado expresamente, paréceme que merece la preferencia, y que es el único que debiera enseñarse» ${ }^{9}$. Me he remontado, pues, al texto de Matheu, en una de sus ediciones, no fechadas, que hay que situar en el XVIII ${ }^{10}, \mathrm{y}$ además, me he remontado más lejos, a la fuente de inspiración no sé si sabida o ignorada por el propio Matheu como es el catecismo de Diego de Ledesma11, datado en 1567-1571, y hoy afortunadamente recuperado. El resultado de la comparación aparece sorprendente, porque el esquema de estos catecismos, desde el de Ledesma, en el XVI, pasando por el de Matheu, en el XVIII, y siguiendo por los tres ahora examinados de Claret en el XIX, tiene una identidad casi absoluta. El siguiente cuadro muestra el esquema primitivo y el resultado final:

LEDESMA, $1570 ?$

Nome del christiano /Segno della Croce/ . Fine ultimo / Mezzi per ottenerlo (=División Doctrina Cristiana).

1) Fede

Credo

Articoli di fede $=12$ artículos

Dio

Trinità

Jesu Christo

Spirito Santo

Chiesa

Purgatorio

Le anime defuncti?

\section{CLARET, Cat. Explicado 1848}

Preámbulo: fin hombre, cristiano; división D.C. Lección preliminar: cruz

1) Doctrina de la fe

Credo

Artículos de la fe (=14)

Dios, cualidades

Trinidad

Encarnación, Pasión

Buenos, malos; obras. Buenas y malas, indulgencias

Purgatorio, infierno, limbo

8. Carta de 19 octubre de 1998 .

9. «Advertencia» en Catecismo de la doctrina cristiana explicado..., Barcelona, Plá, $1849,4^{a}$ ed., 7.

10. Edición de Manresa, Martí Trullás, s.a.

11. L. Resines, El catecismo de Diego de Ledesma, en "Teología y Catequesis" n 61 (1997) 67-99. 
LEDESMA, $1570 ?$

2) Speranza

Pater noster

Ave Maria, Madonna

Salve Regina

Santi, reliquie

3) Due precetti della charità

Amore di Dio

Amore al prossimo

4) Bone opere

$\mathrm{X}$ comandamenti (breve)

Comandamenti della Chiesa

Pecati capitali

Pecato, che cosa sia

Peccato mortale

Peccato veniale

Sacramenti

Altre cose: virtute teologiche e cardinali, dones, bienaventuranzas, frutos, ob. misericordia, potencias, sentidos
CLARET, Cat. Explicado 1848

2) Doctrina de esperanza

Padrenuestro

Ave María

Salve

3) Doctrina de la caridad

Mandamientos

Mandamientos Iglesia

4) Doctrina de obras

a) o. malas: clases pecados, enemigos alma, pecados capitales pecados contra Espíritu S. pecados que claman venganza pecados ajenos

b) o. buenas: sacramentos

virtudes teologales

virtudes cardinales

frutos, dones

bienaventuranzas

obras misericordia

potencias alma, sentidos cuerpo

novísimos

consejos evangélicos

No hay resquicio para la duda, en lo que al esquema se refiere; otra cosa diversa es el desarrollo peculiar de cada texto. El cambio más importante que se ha producido es que Ledesma presentó una tercera parte muy breve, ceñida a hablar de la caridad, en torno al doble mandato del amor a Dios y del amor al prójimo, pero no pasó de ahí (son en total cuatro preguntas), y dejó los mandamientos para la parte cuarta. Matheu alteró el esquema de Ledesma y pasó a la parte tercera los mandamientos, y la parte cuarta quedó vinculada solamente a los sacramentos. Salvado este cambio, la primera impresión resulta no sólo inédita hasta el momento, sino altamente esclarecedora de por dónde han discurrido los precedentes de Claret, que probablemente él mismo desconocía. Con honestidad, y manifestando sus preferencias personales, Claret remitió al texto de Matheu, pero posiblemente no se detuvo nunca en averiguar si éste a su vez redactó un texto original o no. Lo cierto es que Matheu no lo hizo así, y que, posiblemente junto a Ledesma y Matheu, hay que situar el catecismo de los canónigos de Vich, datado en 1790, o algún otro catecismo, como es el caso del de Francisco 
Oriols. El proprio catecismo de Ledesma, difundido y empleado especialmente en Mallorca, desde donde pasó al litoral mediterráneo (aproximadamente desde Barcelona a Valencia), también sufrió muchas y notables modificaciones, aunque mantuviera el esquema de fondo. Tanto éste como aquéllas fueron configurando un catecismo que, con variaciones, circulaba por la tierra de Claret. Años después, cuando él se preocupó por recoger ejemplares de los catecismos empleados en cada diócesis para seleccionar algunos con vistas a la redacción del soñado texto único, rememora los que se empleaban en su diócesis durante los años de su infancia:

«En mi tiempo se enseñaban: $1^{\circ}$, el de los Domeros; $2^{\circ}$ el del Pavorde de Casteltersol, y $3^{\circ}$, el de Smandía o de Barcelona»12.

De los tres en uso, no resulta demasiado difícil deducir que Claret estudió y aprendió de niño el de Matheu, tanto por la preferencia que manifestó, como por el hecho de que tanto el esquema como el mismo texto pasaron a los que después redactó. Todavía más, porque en el Compendio Claret reproduce al pie de la letra el título completo del catecismo de Matheu, y al mismo añade en qué ha consistido su aportación, expresada como «aumentat y metodisat por lo Rt. Anton Claret». Paladinamente se confiesa dependiente de Matheu y admirador del mismo. Y esto vale para los tres catecismos (Brevísimo, Compendio, y Catecismo explicado) que he agrupado en el presente bloque.

Además de la dependencia de Matheu, los catecismos de Claret que ahora nos ocupan (Brevísimo, Compendio y Catecismo explicado) tienen otra nota común: los tres aparecieron en 1848. Esto merece al menos un breve comentario sobre una aparente dificultad: Claret estuvo ausente de Cataluña desde enero de 1848 hasta agosto de 1849 , tiempo en que, a invitación de Buenaventura Codina, marchó a Canarias y llevó a cabo varias misiones en Gran Canaria y Lanzarote. Esto explica perfectamente que el Catecismo brevísimo... se publicara en Las Palmas en 1848. Pero deja en

12. A. M. Claret, Carta al Sr. Jaime Clotet, en J. M. ViÑAS, o. c., 880. Estos catecismos aludidos son respectivamente: $1^{\circ}$ «el de los Domeros», Catecisme de la Doctrina Cristiana que donarem a llum en 1790 los domeros de la catedral de Vich, Vich, Dorca, 1814; $2^{\circ}$ «el del Pavorde de Casteltersol», Francisco OrIols, Diálogos de la doctrina Christiana, que son norma, forma y pauta, ab que los Pares, Amos y Mestres poden facilmente cumplir à la obligació que tenen de ensenyar la Doctrina à sos Fills, Criats y Deixebles. Compostos per lo Doctor..., Cervera, Imp. de la Universidad, s.a.; $3^{\circ}$, «el de Smandía», Francisco MATHEU Y SMANDÍA, Compendi o breu explicació de la doctrina Cristiana en forma de diálogo entre pare y fill, que por la instrucció de sos Feligresos compongué lo Dr...., Manresa, Martí Trullás, s.a. 
penumbra la publicación de los otros dos, el Compendio... y el Catecismo explicado... que aparecieron el mismo año 1848 en Barcelona.

Hay que deducir que se trataba de compromisos que Claret había dejado apalabrados con anterioridad a su partida. El Compendio... fue publicado en la imprenta de los herederos de la viuda de Plá, de Barcelona, con la cual Claret trabajaba habitualmente, y por lo tanto la imprenta se pudo comprometer a terminar y sacar a la luz el encargo, incluso en ausencia de Claret. Respecto al Catecismo explicado..., Claret testifica que ese mismo año (1848) fundó la Librería Religiosa en Barcelona, con la colaboración de los canónigos de Tarragona José Caixal y Antonio Palau, y que continuó utilizando los servicios de la imprenta de Plá13; en diciembre de 1848, aún en Canarias, apareció el Catecismo explicado... (en catalán o en castellano, o en ambas a la vez):

«...por manera que en diciembre de 1848 , hallándome en las islas Canarias, ya empezó a salir el primer libro que la Librería Religiosa imprimió, que fue mi Catecismo Explicado»14.

Acerca del Catecismo brevísimo..., Claret, por indicación de su obispo de Vich se puso a disposición de Codina, obispo electo de Canarias; con él fue a Tenerife en febrero de $1848^{15}$. Claret y Codina pudieron entenderse bien. Ante la escasez de clero, y ante la carencia de medios, Codina debió encargar a Claret la redacción de un catecismo sencillo que pudiera ser empleado por curas y catequistas: es el Catecismo brevísimo... cuyo título expresa la urgencia que Codina y Claret encontraron en Gran Canaria: ... que solamente contiene lo que indispensablemente ha de saber todo cristiano.

El prólogo de Codina a lo escrito por Claret, centra esas circunstancias:

«Para obviar los males que se deben originar necesariamente de la ignorancia de las verdades de nuestra santa fe, y de los principios de moralidad que deben dirigir las acciones humanas, nos apresuramos a dar al público un breve resumen de la Doctrina Cristiana que todos nuestros mui amados hijos en J. C. deben esmerarse a saberlo, no sólo de memoria sino también de inteligencia.

13. Desconozco el detalle de cuándo se produjo el fallecimiento del impresor, Sr. Plá y de su viuda. Pero es seguro que en 1848, ambos habían muerto. Así lo hace constar el pie de imprenta de la primera edición catalana del Compendi ..., en que consta «En la Estampa dels hereus de la V. Plá, 1848».

14. A. M. Claret, Autobiografía, en J. M. VIÑAs, o. c., 321-322.

15. Ibid., 322. 
Lo acaba de componer nuestro mui amado colaborador. D. Antonio Claret, Misionero Apostólico, para utilidad de los fieles habitantes de estas Islas, y principalmente de las gentes de los campos. Recibid, amados hijos, este pequeño catecismo con la misma piedad y devoción con que ansiáis por la palabra de Dios que se os anuncia en las Misiones.

$Y$ vosotros, Venerables Sacerdotes, desplegad un zelo ardiente en instruir con este pequeño catecismo a los fieles, no sólo a los niños y niñas, sino también a los mozos y doncellas, y a los hombres y mujeres de edad madura, pues no son pocos los que ignoran las verdades más fundamentales de nuestra Santa Religión; y esta ignorancia, más que la malicia del corazón, es la causa de la relajación de costumbres que se observa en todas partes. Más adelante se harán venir otros catecismos más extensos del mismo Autor, los cuales podrán entender aun aquellos que no sepan leer, pues con estampas escogidas se ponen a la vista y capacidad de todos las verdades fundamentales de la fe y de la moral cristianas. Y para más estimular a los Señores Sacerdotes y Seculares a aprender y a enseñar este pequeño Catecismo, concedemos 40 días de Indulgencia a todos los que enseñaren y aprendieren la doctrina, cada vez que hagan u oigan la explicación de ella. Y con esta ocasión os damos a todos nuestra bendición Episcopal en el nombre del Padre y del Hijo y del Espíritu Santo. Amén.

Buenaventura, obispo de Canarias».

De este escrito se deducen tres datos: $1^{\circ}$, Codina encuentra un clima de vida cristiana lánguida, y busca en particular en este catecismo un modo de revitalizarla. Nada dice del empleo anterior de otros catecismos. Parece partir de cero. No hay una declaración de «texto oficial«, pero sí «oficiosa».

$2^{\circ}$. La oportunidad la encuentra Codina en la disponibilidad de Claret, y en su larga experiencia. Me inclino por pensar que surgió en forma de encargo de Codina a Claret, con preferencia a que Claret hiciera por su cuenta un texto y se lo ofreciera a Codina.

$3^{\circ}$. Para Codina, este catecismo es el anticipo de lo que se podrá hacer en el futuro, con la llegada de ejemplares del texto que Claret tiene en imprenta, con láminas. Es patente que Claret ha comunicado al obispo lo que pronto será realidad con la publicación del Catecismo explicado..., único que contiene tales láminas, identificado sin duda.

El que redactó Claret en Canarias, no tiene ninguna introducción por parte del autor, fue publicado en Las Palmas, en la imprenta de J. B. Ortega, 1848. Se trata de un texto en $16^{\circ}$, de 104 páginas, con una impresión bastante deficiente. El ejemplar conocido tiene algunas manchas, que no impi- 
den la lectura del escrito. Sin indicación alguna del número de ejemplares de la tirada, la verdad es que en la actualidad es un catecismo casi desaparecido. Su condición de «raro» se refugia en un ejemplar, hoy existente en el Archivo de los Misioneros Claretianos de Roma, a cuyo frente consta una inscripción manuscrita, alusiva al regalo que Claret hizo a su poseedor primero y donante después: «Este es del Párroco Dn. Sebastián de rin (?), gracia del Padre Misionero Claret». Hay otro ejemplar que perteneció a Jesús Quintana Miranda, de Teror.

El esquema de la obra es idéntico al de los otros dos catecismos contemporáneos de Claret, y depende directamente de Matheu, e indirectamente de Ledesma. La semejanza entre los tres textos se entiende por algún borrador que tenía Claret, y por los recuerdos de su propia infancia en que había aprendido el catecismo de Matheu; además, era reciente la reelaboración que él mismo había efectuado sobre el texto de Matheu, en el Compendio... "aumentat y metodisat por lo Rt. Anton Claret», y más amplia en el Catecismo explicado... que contenía el Compendio, en preguntas y respuestas, más las explicaciones de Claret, y las láminas, conectadas con tales explicaciones. A partir de ahí, compuso el Catecismo brevísimo... que coincide en el esquema y en el fondo de la enseñanza con los otros, aunque existan múltiples divergencias, fácilmente comprensibles.

El Catecismo brevísimo... está redactado por preguntas y respuestas («P.», «R.»). Cada una de las partes, aparece reflejada a continuación:

\begin{tabular}{|l|r|r|c|}
\hline \multicolumn{1}{|c|}{ Contenido } & Páginas & $N^{\circ}$ preg. & $\%$ \\
\hline Preámbulo & $7-9$ & 8 & 2.84 \\
\hline Doctrina de la fe (credo) & $9-19$ & 37 & 13,16 \\
\hline Doctrina de la esperanza (padr.) & $19-22$ & 7 & 2,49 \\
\hline Doctrina de la caridad (mandam.) & $22-54$ & 89 & 31,67 \\
\hline Doctrina de las obras (sacramentos) & $55-99$ & 131 & 46,78 \\
\hline Complementos & $99-104$ & 9 & 3,20 \\
\hline TOTAL & & 281 & \\
\hline
\end{tabular}


Se observa la desproporción entre las diversas partes: la parte de los sacramentos casi supone la mitad de la obra; y sumadas las de mandamientos y sacramentos, se llega al 78\%, es decir, algo más de tres cuartas partes de la obra están dedicadas a estas dos materias. Todavía es posible matizar un poco más, porque en los mandamientos, el grueso de las preguntas son las consagradas a los mandamientos quinto y sexto; y en la cuarta parte, de los sacramentos, ocurre lo mismo con los de penitencia y eucaristía que acaparan casi todo el apartado. De las 89 preguntas dedicadas a los mandamientos, únicamente cuatro están consagradas a los mandamientos de la Iglesia, incluido su formulario.

En este escrito, Claret inserta los formularios (credo, padrenuestro, avemaría, mandamientos,...) inmediatamente antes de explicarlos, en lugar de construir un apartado con todos ellos al inicio del catecismo, como era casi habitual en los catecismos. (Claret lo hará después en el Catecismo de la doctrina cristiana).

Si examinamos cada una de las partes, la primera designada con la expresión de preámbulo abarca los aspectos del fin del hombre, la condición de cristiano, la señal de la cruz, y la división de la doctrina cristiana. Esta pregunta en particular ha pasado literalmente desde Ledesma, vía Matheu, hasta este texto de Claret. Tiene una relevancia especial, porque es la que articula todo el esquema de los tres catecismos cotejados (Ledesma, Matheu y Claret), que siguen el mismo plan.

La parte correspondiente al credo, o a la doctrina de la fe, resulta relativamente breve: Claret no incluye, junto al credo, la explicación de los artículos de la fe, que duplica las preguntas. Matheu sí lo había hecho, y Claret le sigue en el Compendio, y en el Catecismo explicado, de manera que hay en ellos cierta duplicidad, y falta de orden, al repetir cosas en lugares diversos. Pero por tratarse de un texto breve, Claret lo omitió en el Catecismo brevísimo. Aún más escueta es la doctrina de la esperanza, dedicada a la oración, con 7 preguntas, tres corresponden a padrenuestro, avemaría y salve, y la explicación son cuatro preguntas más.

Es notable la abultada proporción que tienen los apartados de la doctrina de la caridad (o mandamientos) y la doctrina de las buenas obras (o sacramentos). Ésta última, en realidad, consta de dos subapartados: Ledesma dedicó unas preguntas a las clases de pecados, y otras a los mandamientos de la Iglesia; por su parte, Matheu puso las preguntas sobre las clases de pecados al comienzo de la doctrina de la caridad (parte tercera, relativa a los mandamientos). Claret siguió a Matheu; las vincula a la parte cuarta o doctrina de las obras, en dos categorías: las malas y las buenas 
obras. Entre las malas obras están las clases de pecados, los pecados capitales, y los enemigos del alma. Las obras buenas son los sacramentos.

Finalmente, en el apartado de «complementos» (que sigue a los sacramentos) aparecen los enunciados de las virtudes teologales y cardinales, los frutos y dones del Espíritu Santo, las bienaventuranzas, las obras de misericordia, las potencias del alma, los sentidos corporales y los novísimos, todos sin explicación, reducidos a los simples formularios, como preguntas y respuestas.

Por tratarse de un texto breve, sin explicaciones ni comentarios, no hace referencia al ambiente en que escribió Claret; se podría considerar el Catecismo brevísimo un texto intemporal, parecido a otros anteriores con lo que parecía necesario para un conocimiento suficiente de la fe, según el título «lo que indispensablemente ha de saber todo cristiano».

Es chocante la explicación de Claret sobre la causa de los numerosos matrimonios desgraciados:

«P. Me sabríais decir por qué hay tantos matrimonios desgraciados? R. Porque muchos que se casan no se disponen a recibir este sacramento en estado de gracia, ni buscan en el matrimonio el fin que deben, que es servir a Dios en aquel estado».

Ha aparecido ya este Catecismo brevísimo como heredero del de Matheu; Claret lo tuvo en cuenta al servirse de él como fuente de inspiración. Una diferencia es que Matheu estableció un diálogo entre padre e hijo ${ }^{16}$; no hizo lo mismo Claret en esta ocasión ${ }^{17}$, pues sólo habla de «pregunta-respuesta». A Claret llegó la influencia de Ledesma, a través de Matheu en la pregunta relativa a quién es Dios, y en las preguntas relativas a las clases de pecados.

Hay que destacar el acento bíblico del Catecismo brevísimo... de Claret, pues aparecen algunas alusiones en las penas para el blasfemo (segundo mandamiento), el perdón a los enemigos (quinto mandamiento), la gravedad del escándalo (quinto mandamiento), la gravedad de los pecados contra el sexto mandamiento, la preocupación por los bienes ajenos (séptimo mandamiento), la gravedad del adulterio (noveno mandamiento), más una cita bíblica literal sobre la autoridad de la Iglesia, y un par de alusiones al antiguo testamento. Aun siendo breve, Claret, en este Catecismo brevísimo..., emplea mucho más la Biblia que la mayoría de sus contemporáneos, que ni siquiera aludían a ella.

16. Así consta en el título, donde dice «...en forma de diálogo entre pare y fill...».

17. Lo hace Claret en sus Compendio o breve explicación... y en Catecismo de la doctrina cristiana explicado..., pues ambos se ajustan al texto de Matheu. 
Como síntesis de lo dicho, destacan los siguientes puntos:

1.- Se trata de un texto breve, pero no esquemático; contiene explicaciones cortas en general; está muy desarrollado lo relativo a los mandamientos y a los sacramentos de penitencia y eucaristía. Destaca el acento moral en los pecados que se pueden cometer, el modo de obtener el perdón, y cómo recibir la comunión.

2.- Hay un tenue tinte bíblico que aparece en una serie de alusiones, casi como pinceladas aisladas, más una doble cita textual.

3.- Se aprecia una diferencia (en amplitud y en desarrollo) respecto a los dos otros textos de Claret, el Compendio y el Catecismo explicado. Éstos aparecen profundamente emparentados entre sí, mientras que el Catecismo brevísimo guarda un parecido parcial, que le hace próximo pero independiente de ambos.

4.- Hay una dependencia evidente respecto al catecismo de Francisco Matheu, su fuente de inspiración.

5.- El resto coincide con lo substancial que aparece en otros catecismos del XIX, sin grandes diferencias de planteamiento, de expresión o de criterios.

\section{El Compendi o bREU EXPLICACIó... (BARCELONA, 1848)}

Todavía más que en el anterior, en este catecismo aparece la vinculación entre Matheu y Claret, que se declara ferviente admirador.

Publicados ambos en 1848, cabría que el Compendio fuera una abreviación del Catecismo explicado; o, a la inversa, que el Catecismo explicado resultara una ampliación del Compendio. Me inclino por la segunda opción, pues en ciertos temas parece que la doctrina que incluye el Compendio podría resultar suficiente; eso mismo es ampliado en el Catecismo explica$d o$, con una matización aún más aquilatada. Los pasos serían: $1^{\circ}$ Claret asume el texto de Matheu, que le parece el mejor; $2^{\circ}$ Interviene modificándolo y añadiéndole preguntas: es el Compendio..., redactado en forma de preguntas y respuestas; $3^{\circ}$ Sobre la base del texto modificado (Compendio) introduce algunas preguntas más, le adiciona las láminas y sus explicaciones, en estilo expositivo: es el Catecismo explicado.

Existe, por tanto, una parte amplia, original de Matheu, común a estos dos textos de Claret. Reconocer esa dependencia no impide examinar las diferencias entre ellos. La parte común a los dos catecismos de Claret se 
ciñe a las preguntas y respuestas, y no a las exposiciones del Catecismo explicado. Las semejanzas comienzan desde el mismo título ${ }^{18}$ :

Las diferencias, en negrita, aluden al destino que entonces desempeñaba Matheu, y a la intervención posterior de Claret. Éste no trata de disimular la fuente de que se sirve; pero después no diferenció con ningún signo (asterisco, tipo de letra,...) lo original de lo modificado, y quien no tenga a la vista una edición de Matheu y otra de Claret no es capaz de distinguir una y otra parte.

Título de Matheu

Compendi o breu explicació de la Doctrina Cristiana, en forma de dialogo entre pare y fill, que per la instrucció de sos feligresos compongué lo Dr. Francesch Matheu y Smandí, prebere y rector que fou de la iglesia de sant Pere de Bigas y vuy de sant Baldiri de Llobregat, bisbat de Barcelona,
Título de Claret

Compendi o breu explicació de la Doctrina Cristiana, en forma de dialogo entre pare y fill, que per la instrucció de sos feligresos compongué lo Dr. Francesch Matheu y Smandia, prebere y rector que fou de la iglesia de sant Pere de Bigas y de sant Baldiri de Llobregat, bisbat de Barcelona, aumentat y metodisat per lo Rt. Anton Claret,

La cantidad de materia aumenta desde Matheu a los dos catecismo de Claret:

\begin{tabular}{|l|c|c|c|}
\hline$N^{o}$ de preguntas & Matheu & Compendio & Cat. explic. \\
\hline Preámbulo & 15 & 17 & 17 \\
\hline Fe (credo) & 121 & 126 & 136 \\
\hline Esperanza (oración) & 63 & 61 & 69 \\
\hline Caridad (mandamientos) & 67 & 169 & 201 \\
\hline Obras (sacramentos) & 92 & 188 & 98 \\
\hline Complementos & 81 & 94 & 714 \\
\hline TOTAL & 439 & 655 & 203 \\
\hline
\end{tabular}

18. Para evitar confusiones, emplearé la abreviación de Compendi para referirme a la obra de Matheu, publicada sólo en catalán; y la de Compendio para referirme a la de Claret, que tuvo ediciones catalanas y castellanas. 
Claret cambió de orden algunas preguntas, trasvasándolas de un apartado a otro, por lo que las cifras parciales no son absoluto reflejo de la verdad. Eso no impide reconocer el aumento producido en los apartados de los mandamientos y sacramentos: es síntoma de un claro acento moralizante que Claret intensifica, pues el texto de Matheu se aumenta en 218 preguntas en el Compendio, y 59 más en el Catecismo explicado.

A modo de prólogo, Claret pone esta «Advertencia» en el Compendio, en la edición catalana de 1848:

«Ab molta atenció y cuydado he llegit los diferents catecismes dels Bisbats de Catalunya y de altres provincias de Espanya y fora de ella; peró entre tots ningun me ha agradat tant com lo que compongué lo Dr. D. Francisco Matheu y Smandía, Rector de S. Pere de Bigas del Bisbat de Barcelona; y no sols me ha agradat á mi, sinó que també haurá gustat á molts altres, puig he observat, que á mes de ser adaptat y seguit en tot lo bisbat de Barcelona, ho es també en moltas parroquias y estudis ben distants de dita ciutat: per lo tant aqueix me apar que se hauria de adaptar, y únicament aqueix; y axí se evitará la confusió y mal que porta la diversitat de catecismes, perque encara que tots en substancia diuhen lo mateix, y es sólida y católica la doctrina que portan; peró lo accidental ó lo modo de preguntar y respóndrer es molt diferent, seguintse de aquí uns danys incalculables, como tothom coneix.

No obstant, á pesar de ser aqueix lo millor entre la multitut de catecismes, no queda de trovársehi á menos alguna cosa en quant á la explicació de alguns punts molt interessants; vull dir que no se explica tant com convé, y aqueixa falta he pensat remediarla, umplint los vacuos que hi trobo ab preguntas y respostas tretas de altres catecismes: imitant en axó á la ingeniosa abella, que xupa en diferentas flors pera formar la dolsa bresca. Mes axí com en la bresca no sols hi procura la dulsura de la mel, sinó també lo bon orde de las casetas, lo mateix me he proposat jo; extraurer de las flors dels demés catecismes la mel, á fi de perfeccionar y deixar en tota dulsura lo present catecisme: y perque res falte en ell, donar un millor orde en la col-locació de algunas materias. Y no reparo en prométrer que aquells que apendrán y practicarán aquestas cosas, haurán trobat paraulas pera respóndrer ara y en lo dia del judici: Qui didiscerint ista, invenient quid respondeant (Sap. c. 6, v. 11)»19.

Claret no disimula su predilección por el catecismo de Matheu, al que introduce cambios («umplint los vacuos que hi trobo ab preguntas y res-

19. Matheu incluye las palabras del libro de la Sabiduría en la portada de su Compendi. 
postas tretas de altres catecismes»). No pretendía su lucimiento, sino el deseo de ofrecer una mejor formación religiosa con el texto por él «aumentat y metodisat». Posiblemente, al hacer los cambios Claret pensaba simultáneamente en el Compendio y en el Catecismo explicado, de manera que, con un mismo proyecto, realizara dos textos, uno reducido, únicamente con preguntas y respuestas (el Compendio), y otro extenso, con más preguntas, además de láminas y explicaciones anejas (el Catecismo explicado). La intervención de Claret consistió en: - a) añadir preguntas; - b) cambiar algunos matices en ciertas preguntas o respuestas; - c) alterar el orden.

En el añadir preguntas, las 218 nuevas preguntas no son siempre «nuevas». Claret lo había advertido, al señalar que añadió «preguntas y respostas tretas de altres catecismes». He podido averiguar que bastantes proceden del Catecisme de la doctrina christiana en forma de dialogo entre pare $y$ fill, que donarem a llum lo any 1790 los domers de la Catedral de Vich, Vich, Dorca, 1814. Otras provienen del escrito por Francisco Oriols, Dialogos de la doctrina christiana que son norma, forma, y pauta, ab que los Pares, Amos y Mestres poden facilmente cumplir a la obligació que tenen de enseñar la Doctrina a sos Fills, Criats y Deixebles, Cervera, Imp. de la Universidad, s.a. Otro bloque de preguntas proceden del segundo Astete (antes conocido como Ripalda). En consecuencia, la originalidad de Claret queda muy mermada, reducida al papel de un hábil recopilador.

Cuando cambia matices en determinadas expresiones, aparece, en general una actitud perfeccionista, deseosa de aquilatar la doctrina de modo más exquisito. Se perciben los cambios de fondo doctrinal entre el catecismo de Matheu, y el Compendio, y entre éste y el Catecismo explica$d o$, con voluntad de depurar los conceptos ${ }^{20}$. Es un afán de perfección por mejorar su Catecismo explicado.

Otras aportaciones consisten en cambiar de orden algunas cosas. Al indicar que el texto primitivo había sido «aumentat y metodisat», no altera el sistema de preguntas y respuestas, ni tampoco sigue otro plan. La anunciada metodización consiste únicamente en cambiar de lugar algunas preguntas, según un criterio lógico un poco más exacto. Así, la pregunta que interroga dónde está Dios aparece en el catecismo de Matheu después de haber hablado de las tres personas de la Trinidad, inmediatamente antes

20. Como el diálogo en Matheu discurre entre padre e hijo, las iniciales de las preguntas y respuestas son «P.» para designar «Pare» $\mathrm{y}$ «F.» para designar «Fill»; las mismas abreviaturas mantiene Claret en sus catecismos compuestos en catalán; pero cambia a «P.» (= «Padre») y «H.» (=«Hijo») en las ediciones castellanas. 
de hablar de la encarnación de Jesús. Dicha pregunta se conserva en el mismo contexto en el Compendi, pero en el Catecismo explicado la traslada y la sitúa después de hablar de que Dios es fin de todas las cosas (atributos divinos). El nuevo emplazamiento parece dejar a Claret más satisfecho de la forma de presentar la doctrina en el nuevo orden. También es un ejemplo el bloque de preguntas sobre quiénes son los buenos y los malos, que tiene en Matheu un evidente desorden; siguiendo un criterio más acertado, Claret pasa las preguntas sobre quiénes son los buenos y los malos al final de la exposición de los artículos de la fe. Otro ejemplo de desplazamiento metodológico se encuentra en las preguntas o «tratado» sobre el pecado. Matheu lo había situado después de haber incluido el formulario de los mandamientos. Claret, por su parte sitúa este «tratado» sobre los pecados al comienzo de la cuarta parte del catecismo, la de la doctrina de las obras.

Finalmente, en los aspectos complementarios de la doctrina cristiana, Claret altera sensiblemente el orden que había presentado Matheu:

Matheu

Dones del Espíritu Santo

Obras de misericordia

Potencias del alma

Sentidos corporales

Virtudes teologales

Virtudes cardinales

Frutos del Espíritu Santo

Bienaventuranzas (Pecados capita-

les, ya trasladados)

(Pecados contra el Espíritu Santo, ya

trasladados)

(Pecados que claman venganza, ya

trasladados)

Novísimos
Claret

Virtudes teologales

Virtudes cardinales

Frutos del Espíritu Santo

Dones del Espíritu Santo

Bienaventuranzas

Obras de misericordia

Potencias del alma

Sentidos corporales

$* * * *$

$* * * *$

$* * * *$

Novísimos

El resultado es que brota un nuevo «tratado» que no constaba en el catecismo de Matheu. Éste, siguiendo el plan que trazara Ledesma, dividió la doctrina cristiana en cuatro partes, la última de las cuales era la «doctrina de las obras», que se ceñía a los sacramentos. Claret, por su parte, subdividió este apartado en dos: 1) las obras malas o pecados; y 2) las obras buenas o sacramentos, y otros comportamientos cristianos. El apartado de las obras malas recogía la enseñanza sobre los pecados, más los pecados 
capitales, los pecados contra el Espíritu Santo y los pecados que claman venganza a Dios. Además, dos preguntas sobre los enemigos del alma (que aparecían en el texto de Matheu en la sexta petición del padrenuestro). Por último, Claret añadió lo que se refiere a los pecados ajenos (que no figuraba en Matheu). Un tratado nuevo, hecho de retazos procedentes de diversos lugares del catecismo de Matheu.

El apego de Claret hacia el texto de Matheu le llevó a conservarlo, con modificaciones. En consecuencia, después de explicar los doce artículos del credo, los repitió según los catorce artículos de la fe. Se producen repeticiones, avances y retrocesos. Pesó la fidelidad al texto de Matheu más que la distribución de las preguntas en un orden lógico. Claret era un catequista fogoso más que un catequeta que hubiera efectuado una sólida reflexión sobre el catecismo. Hay otras modificaciones introducidas por Claret.

Una es la «advertencia» de marcado cuño moral, al final de los mandamientos; figura en el Compendio, pero no en el Catecismo explicado. Sin embargo, no es original de Claret, pues aparecía, casi igual en el catecismo de Francisco Oriols:

«ADVERTENCIA. Per fi del manaments se ha de advertir que aquell que haurá fet alguna cosa de las que se ha dit que era pecat, y no ho tenia ni dubtava que fos pecat ni cosa mala, ni estaba en la sua ma lo dubtarne, no té obligació de confessarse de lo passat, sinó de lo que fará de aquí endevant, y al contrari, lo que havia fet pensantse ó dubtant que era pecat ó mal, y ara sab que no ho es, déu confessarse de lo passat, si es falta mortal, per conciencia errónea».

Otra modificación alteró los apéndices finales del catecismo de Matheu:

Matheu

- $1^{\circ}$, reglas de ben viurer (normativa de tipo espiritual para proceder de la mejor forma posible).

- $2^{\circ}$, actes de fe, esperanza y caritat (Claret los abrevia e introduce como preguntas en la doctrina relativa al primer mandamiento).

- $3^{\circ}$, modo de resar lo rosari.

$-4^{\circ}$, tres diferents formulas de ayudar á Missa (según el misal romano, según el rito de los carmelitas y según el de los dominicos).

- y $5^{\circ}$, gracias per la taula.

\section{Claret, Compendio}

- $1^{\circ}$, modo de ajudar a la missa segons lo missal romá (elimina, por tanto, lo correspondiente a los ritos de carmelitas y de dominicos).

- $2^{\circ}$, algunas reglas que déu observar lo ministre ó lo qui serveix la missa resada, tretas del Illm. Galindo, y de Baldeschi.

$-3^{\circ}$, gracias per la taula (conservada igual)

$-4^{\circ}$, oración a la Verge Santissima pera alcansar la sua protecció. 
Remite a Galindo ${ }^{21}$ y Balsechi22 y sus indicaciones sobre el comportamiento, actitud y conocimientos prácticos para el monaguillo23.

La conclusión es que Claret deseaba mejorar el catecismo de Matheu. Parte de lo escrito por Matheu, pero se mueve con una libertad absoluta, para introducir numerosísimas preguntas, cambiar el orden de algunas otras, e incluso crear un nuevo «tratado» sobre el pecado o las obras malas que no figuraba en el texto precedente, y también añadir matices que no encontraba en la redacción de Matheu. El resultado es un catecismo parecido, pero distinto; el Compendio de Claret no puede negar su ascendencia en el Compendi de Matheu, pero con muchos cambios. El de Claret es un texto de catecismo distinto del de Matheu.

Hay que volver un momento la vista al Catecismo brevísimo, contemporáneo de su Compendio. Teniendo ambos a la vista, bastantes preguntas nuevas con relación a Matheu, no son tan nuevas con relación al Compendio: Claret tenía ante sí una copia manuscrita, o recordaba la redacción que había dejado en la imprenta en Barcelona, mientras escribía en Las Palmas el Catecismo brevísimo.

\section{El Catecismo explatcado (BARCElona, 1848)}

Este otro catecismo de Claret es una transformación del Compendio: «Sobre la base del texto modificado (Compendio) introduce aún algunas preguntas más, y, sobre todo, le adiciona las láminas y explicaciones, en estilo expositivo: el resultado es el Catecismo explicado». Añado algunas matizaciones y análisis.

21. Se refiere a la obra de GREGORIO GALINDO, Rúbricas del Misal romano reformado. Añadido en esta décima edición con un compendio de la vida de este Prelado. Corregida y aumentada por Juan Sánchez Bravo, Madrid, Josef Doblado, 1779. De la obra se hicieron numerosas ediciones, que repetían con frecuencia el remoquete de «décima edición», no siempre exacto.

22. G. BALSECHI, Exposición de las Sagradas Ceremonias de la Misa privada, solemne y pontifical, Visperas, oficios de Semana Santa y principales fiestas del año, Madrid, Imp. de la Compañía de Impresores y Libreros del Reino, 1868. Claret, sin duda, consultaría alguna edición anterior, que no he localizado, quizá en italiano, de donde procedía la obra original.

23. Estas reglas tienen un notable parecido con «Lo que debe practicar el que ayuda a Misa", que consta en la Explicación de la doctrina christiana, según el método con que la enseñan los Padres de las Escuelas Pías, de Cayetano Ramo, Madrid, Vda. de Barco López, 1808. 
En primer lugar, el título es Catecisme de la doctrina cristiana explicat y adaptat a la capacitat dels noys y noyas y adornat ab moltas estampas per lo reverent D. Anton Claret, prebere ${ }^{24}$. El título castellano es idéntico. (Por brevedad lo cito como Catecismo explicado). La primera apreciación es que del título, no así en el resto, desaparece la referencia a Matheu, que figuraba en el Compendio. No intentó que la obra originante pasara inadvertida, pues Claret deja constancia de sus intenciones, al incorporar el núcleo original de Matheu:

«...Sabiendo que os gustan las láminas, lo he adornado con ellas; y como lo que se come con gusto es lo que nutre, como dice el adagio, deseando yo nutrir vuestras almas con el alimento de esta explicación de la doctrina cristiana, la he compuesto de modo que os sea agradable.

Estas láminas no las he puesto precisamente para los niños, si que también para los mayores, y con especialidad para vosotros, padres de familia (...) para que cuando vuestros hijos os preguntaren ¿qué significan esas figuras? les respondáis explicándoles por medio de ellas la Religión cristiana, que tenéis obligación vosotros de enseñársela y ellos de aprenderla.

$\mathrm{Y}$ al fin que al mismo tiempo, queridos niños, sepáis lo material de las preguntas y respuestas, he puesto a continuación el catecismo del Dr. Francisco Matheu y Smandía, con algunas adiciones a ciertos puntos...».

y en la «Advertencia» que sigue al prólogo:

«A cuantos lean este catecismo debo advertirles que la explicación de las láminas y de algunos otros puntos es de mi pobre caudal; pero el diálogo, como ya se advierte en el prólogo, es del Dr. Francisco Matheu y Smandía, que entre los muchos catecismos que he visto y mirado expresamente, paréceme que merece la preferencia, y que es el único que debiera enseñarse» 25 .

24. El Diccionari de Catequetica, Barcelona, Edebé, 1987, en su artículo «La catequesi a Catalunya», de JOAN BUSQUETS, introduce un error al señalar que esta obra «fou editat el 1848 (en castellà el 1850)». Lo cierto es que el mismo año, 1848, aparecieron las dos ediciones catalana y castellana, y que ésta segunda tuvo mayor aceptación, puesto que el año siguiente, 1849 , salía a luz la segunda edición catalana mientras que la edición castellana del mismo 1849 era ya la cuarta. Parecido error consta en JOAN RODRÍGUEZ, Catecisme, en R. CORTS Y OTROS (eds.) Diccionari d'història eclesiàstica de Catalunya, Barcelona, Generalitat - Ed. Claret, 1998, v. I, 493; no diferencia bien los títulos, ni las fechas de aparición e indica fechas diversas para las ediciones catalana y castellana, lo cual no es exacto.

25. Desde la edición castellana $17^{\mathrm{a}}$, de 1865 , cambió la «Advertencia» por otra en la que sintetizaba los pasos dados para elaborar el catecismo único (que aparecerán más adelante); además, incorporó en las preguntas y respuestas las del texto único que editó autónomo en 1866 . 
Aparecen delimitados los tres aspectos que conviene tener presentes: $1^{\circ}$, las preguntas y respuestas; $2^{\circ}$, las láminas; $3^{\circ}$, las explicaciones adjuntas.

\section{1․ LAS PREGUNTAS Y RESPUESTAS}

Son las preguntas originales de Matheu, alteradas por Claret, para el Compendio, con las adiciones y cambios de orden que Claret introdujo. Sus palabras («con algunas adiciones en ciertos puntos») podrían entenderse como leves retoques, cuando en realidad los cambios son abundantes. Pero Claret no se limitó en el Catecismo explicado a volcar todo lo que aparecía en el Compendio. Además de suprimir los apéndices, y la «advertencia» de tono moral al final de los mandamientos, en las preguntas y respuestas, todavía añade nuevas preguntas con relación a las que aparecían antes; son otras 59 preguntas nuevas. También en alguna ocasión funde dos preguntas del Compendio en una sola en el Catecismo explicado.

Destaco entre esas preguntas una sobre la validez de una iglesia posterior a Jesucristo (en clara alusión al protestantismo), o la célebre cuestión de que fuera de la Iglesia no hay salvación. También figuran algunas sobre ciertos atributos de Dios que no aparecían en la obra anterior. Otro bloque de preguntas se centra en torno a María, y la devoción que se le ha de profesar. Hay algunas preguntas más sobre los mandamientos, entre las que destaca una serie sobre las obligaciones entre esposos. Algunas más aparecen en la parte correspondiente a los sacramentos. Algunas las trasvasa Claret desde su Catecisme menor..., de corte elemental, pero que no duda en reemplear. Esto permite apreciar el afán de permanente perfección de Claret.

Igual que hizo en el Compendio, ahora aparecen modificaciones en la redacción de determinadas preguntas que alteran su sentido primero. Al no ser muchas es posible citarlas una a una. Así, la frase del credo según la cual Jesús está sentado a la derecha del Padre; la nota de catolicidad de la Iglesia se modifica desde la versión más antigua, a la más moderna del Catecismo explicado; también hay cambios con relación a la nota de apostolicidad; es significativo el cambio en la pregunta sobre el número de dioses aunque no cambie substancialmente (Dios es llamado «todopoderoso», y luego, «verdadero»).

Los cambios indicados afectaron a las ediciones castellana y catalana; los que siguen sólo se produjeron en la versión castellana del Catecismo explicado. Este hecho, repetido hasta siete veces, permite establecer que la edición castellana es posterior a la catalana (aunque ambas daten de 1848) 
y en ella ha introducido Claret una serie de rectificaciones que no alcanzaron a la ya publicada versión catalana. Estos cambios son: la definición de qué es orar (tomada del catecismo de Astete); la cuarta petición del padrenuestro; el comienzo de la segunda parte del ave maría; el bautismo de urgencia (con dos modificaciones); la celebración de la unción de enfermos; y los novísimos. Claret estuvo atento a las ediciones que se sucedían, y resulta patente el deseo de mejorar el Catecismo explicado. Son matices que contemplan la práctica ritual o que tocan cuestiones vinculadas con las creencias, según los casos. Pero en todas las ocasiones el deseo de perfección denota una labor de constante revisión.

Casi todas las preguntas del Catecismo explicado figuraban ya en el Compendio; y la mayor parte de ellas aparecían ya en el Catecismo brevísimo. Desde el punto de vista bíblico, importa poner la atención en algunas preguntas que no constaban en el Catecismo brevísimo. Así, al final de los mandamientos de la ley de Dios, hace referencia a la síntesis en el doble mandamiento del amor; Claret tuvo la ocasión de haber remitido a Mt. 22, 37-40, pero se contentó con hacer una alusión, que no es referencia textual, y que deja desvaída la fuerza de la Palabra de Dios. Con ocasión del cuarto mandamiento de la Iglesia, sobre el ayuno, indicó que hay personas que desprecian los ayunos; Claret incluyó un razonamiento muy flojo: cita Flp. 3, 18-19, señalando que herejes y protestantes son enemigos de la cruz de Cristo. También en el cuarto mandamiento aduce un argumento, supuestamente bíblico, por el que Jesús comunicó a su Iglesia el poder de establecer concretamente ayunos y abstinencias (se apoya en Lc. 10, 16 y Mt. 18,17). Sobre la conveniencia de la acción de gracias después de la comunión, alude a Jn. 13, 30, y equipara la conducta de Judas con la de los que comulgan y no dan gracias después ${ }^{26}$.

\section{2․ LAS LÁMINAS}

Las láminas, según las palabras de Claret, están pensadas no tanto para los niños, cuanto para los padres, a fin de que ellos, con las láminas, y la explicación, pudieran enseñar a sus hijos; los niños son destinatarios indi-

26. Otra referencia, no bíblica, es la que alude a las palabras de Santa Teresa, a propósito de las malas confesiones: «P. Son moltas las personas ques perden per las malas confessions? F. Si pare; santa Teresa diu que la major part dels cristians se perden per las malas confessions». Podría estar aludiendo a la idea de Santa Teresa: «paréceme que mil vidas pusiera yo para remedio de un alma de las muchas que vía (sic) perder» (Camino de perfección, 1,2), aunque no alude directamente a la confesión. 
rectos de las láminas. También los analfabetos y personas de escasa formación, como dice en el Catecismo brevísimo:

«Más adelante se harán venir otros catecismos más extensos del mismo Autor, los cuales podrán entender aun aquellos que no sepan leer, pues con estampas escogidas se ponen a la vista y capacidad de todos las verdades fundamentales de la fe y de la moral cristianas».

Las láminas son del propio Claret, quien ya desde joven asistió a clases de dibujo, gramática y francés en la Casa Lonja, mientras preparaba su futuro profesional en la industrial textil. Semejante habilidad la aprovechó para realizar las láminas que jalonan las lecciones del Catecismo explicado ${ }^{27}$. Son a página completa (excepto tres, en la explicación del bautismo de escasos centímetros, que forman parte de la explicación); figuran en la página par que precede a cada lección, que se inicia en la página impar opuesta. Llevan el título del tema representado, y al pie, una frase bíblica, con su cita. Algunas láminas, como las de los sacramentos, son representativas ${ }^{28}$ de la respectiva celebración. Pero la mayor parte contienen un número variable de símbolos, alusiones y alegorías que remiten a la explicación que sigue al dibujo. Por ejemplo, la que precede a los mandamientos tiene un motivo central con las tablas de la ley entre Cristo y Moisés, mientras que al fondo hay un ojo y un corazón, que simbolizan la presencia de Dios y la ley natural impresa en los corazones; rodeando este motivo central, diez pequeños dibujitos, numerados, remiten a cada uno de los mandamientos.

Las láminas son similares a otros grabados tan del gusto de la época. Están realizadas a plumilla. Denotan un talento artístico; pero sobre todo expresan la voluntad del autor de poner su habilidad al servicio de una causa superior, como era mejorar el aprendizaje de la catequesis. Ciertamente, el suyo constituye un raro ejemplo de catecismo durante el siglo XIX, porque son escasos los que incluyen dibujos o grabados ${ }^{29}$, y ninguno

27. «Deseoso de adelantar en los conocimientos de la fabricación, dije a mi padre que me llevase a Barcelona. Condescendiendo mi padre, me llevó allá; yo mismo, como San Pablo, me ganaba con mis manos lo que necesitaba para comida, vestidos, libros, maestros, etc. La primera cosa que hice fue presentar una solicitud a la Junta de la Casa Lonja para ser admitido en las clases de dibujo. Lo conseguí y me aproveché algún tanto. Y ¡quién había de decir que el dibujo que yo aprendía para la fabricación, Dios lo disponía para que sirviera para la Religión! Y, en efecto, mucho me ha servido para dibujar estampas del Catecismo y de otros asuntos místicos»: A. M. ClareT, Autobiografía, en J. M. VIÑAS, o. c., 199-200.

28. La edición $4^{a}$ castellana omite la lámina que precede a la lección de la eucaristía.

29. Bastantes ediciones del Catecismo histórico de C. FLEURY, unas con el texto completo y otras en extracto, incluyen láminas. Muchas de estas ediciones proceden del XIX, aunque también existen ediciones del XVIII dotadas de láminas. 
del tamaño y claridad plástica que las láminas poseen. No hizo algo así en los otros catecismos que editó. Las mismas láminas están en la edición catalana y en la castellana; evita rótulos escritos (que podrían servir para una versión, pero no para la otra); o recurre a breves rótulos en latín, que valían para las dos versiones (así: «liber vitae», «Christus-Ecclessia (sic)», «Symbolum Apostolorum in duodecim distinctum articulos iuxta assignationem S. Augustini»,...).

Desde la decimosexta edición castellana, de 1863, las láminas han sido substituidas por otras, similares, que contienen los mismo motivos en cada dibujo respectivo, pero que responden a otra mano. La sustitución se hizo aún en vida de Claret. Ninguna anotación advierte del cambio a los lectores de ésta y sucesivas ediciones; los responsables de la publicación estimaron que la sustitución de unas por otras no resultaba fundamental.

\section{$3^{\circ}$. LAS EXPLICACIONES}

Debidas a la pluma de Claret, ocupan un curioso lugar intermedio. Cada lección sigue este orden: $1^{\circ}$, una lámina; $2^{\circ}$, la explicación, ordinariamente amplia, a lo largo de varias páginas; vinculada directamente a la lámina, la explicación da la clave para interpretarla; $3^{\circ}$, las preguntas y respuestas (casi todas) del Compendio.

La explicación se vincula a la lámina correspondiente; sin ella la lámina no siempre sería percibida en su totalidad. A la vez constituye una exposición, relativamente amplia, de lo que las preguntas y respuestas proponen como resumen. Aunque en su origen no fue así, pues las preguntas originales de Matheu no tenían esa función de síntesis, y las que añadió Claret a Matheu en el Compendio tampoco estaban vinculadas a una explicación, en el Catecismo explicado cumplen esa función.

Para cada lección están asignadas las preguntas que abordan el tema de la lámina y la correspondiente explicación. Esto produce un desequilibrio: unas explicaciones sólo van seguidas de dos preguntas, y otras explicaciones van acompañadas de más de un centenar de preguntas (tal es el caso de la lección decimosexta correspondiente al credo, con las preguntas sobre los artículos de la fe; también sucede algo parecido en la lección sobre los mandamientos de la ley de Dios, seguidos de una magra enumeración). Sin duda, este desequilibrio es un desacierto pedagógico notable, pero Claret lo mantuvo, sin darle demasiada importancia.

Las explicaciones tiene un notable acierto: están redactadas en segunda persona en muchísimas ocasiones, de manera que se establece a través 
del libro un diálogo directo entre el autor y el lector. Es una forma de que las explicaciones tengan mayor poder incisivo para sugerir, invitar a la oración, estimular a la recepción de un sacramento, o a la adopción de un estilo de comportamiento cristiano. No son explicaciones excesivamente eruditas, aunque no están exentas de citas de fuentes o de autores cristianos, que van, por ejemplo, desde el concilio de Éfeso, hasta el legislador pagano Licurgo, pasando por las páginas de la Biblia, o por la referencias al poco conocido Peraldo, obispo de Londres. Claret puso un matiz más propiamente teológico (sin remontarse a cuestiones difíciles), o moral, y otras veces invitó a la piedad o a la práctica religiosa.

Aunque son muchas las ocasiones en que cita la Biblia, no puede decirse que sea una explicación que gravite sobre la palabra de Dios; ésta no es citada por Claret con el carácter de fuente que hoy se reclama para la Biblia. Para Claret, como para la catequesis del XIX, era una fuente más, aprovechable; la diferencia es que Claret la aprovechó bastante más que muchos de sus contemporáneos que nunca la citaban. Junto a razones seguras o teológicamente válidas, aparecen otras en el discurso de Claret que no pueden ser tenidas por tales, como es que resucitaremos a la edad de 33 años, aunque la reflexión teológica de la época (y de siglos anteriores) tenía el dato como seguro e indiscutible. Algo semejante ocurre cuando habla de la verdadera iglesia frente a las sectas y herejías, que, conforme a la mentalidad de la época, deben ser enteramente rechazadas y despreciadas. Se percibe en las explicaciones de Claret un recurso a las predicaciones que le habían resultado útiles en las misiones populares, de manera que el conjunto de la obra tiene ese sentido de mezcla entre las explicaciones sobre la fe cristiana y las apelaciones al sentimiento efectista. Es lógico que se sirviera de lo que le había resultado útil, para componer este Catecismo explicado.

Hay algunas lecciones que carecen de preguntas y respuestas al final, porque Claret quiso introducir una explicación más amplia, y no desplazó las preguntas o no deseó desdoblar en dos grupos las preguntas de un mismo tema. Así, aparecen sin preguntas una lección sobre la Trinidad (luego salen preguntas sobre la Trinidad en las que comentan los artículos de la fe), otra lección sobre la Iglesia; otra lección sobre los consejos evangélicos (apartado que no había sido abordado por Matheu y, por tanto, carecía de preguntas); y finalmente otra lección sobre el resumen de la doctrina cristiana y la presentación del año litúrgico (que tampoco figuraba en el catecismo de Matheu). 


\section{CATECISMo de LA DoCtrina CRISTIANA (MADRID, 1866)}

Es el último catecismo compuesto por Claret. Para situarlo es necesaria una previa explicación sobre sus pretensiones de conseguir un texto único de catecismo. $\mathrm{El}$ asunto no era nuevo, puesto que el problema había sido detectado con anterioridad a Claret por otros autores de catecismo (Antonio Juan Pérez y Pérez, en el siglo XVIII, y Vicente Solano, en 1835). Lo cierto es que estos intentos, o, con más exactitud, amagos anteriores no tuvieron eco eficaz. De ahí que la diferencia entre ellos y lo que hizo Claret estribe, sobre todo, en que éste pasó a la acción.

Desde mucho tiempo atrás, en su actividad como catequista, y como misionero, se había percatado de los inconvenientes que esto traía en la práctica; $y$ había manifestado por escrito no sólo su preocupación, sino también su deseo, a fin de que alguien recogiese el reto. Se expresaba en la «Advertencia preliminar» del Compendio (1848):

«Ab molta atenció y cuydado ha llegit los diferents catecisms dels Bisbats de Catalunya y de altres provincias de Espanya y fora de ella (...) Per lo tant aqueix [el de Matheu] me apar que se hauría de adaptar, y unicamente aqueix; y axí se evitará la confusió y mal que porta la diversitat de catecismes, perque encara que tots en substancia diuhen lo matiex, y es sólida y católica la doctrina que portan, peró lo accidental ó lo modo de preguntar y repondrer es molt diferent, seguintse de aquí uns danys incalculables como tothom coneix...».

De la misma forma, la «Advertencia» que figura al frente del Catecismo explicado denota la experiencia que había adquirido en sus años de ministerio sacerdotal, y sobre todo en la etapa de 1840 a 1848 , en que como misionero acudió de un sitio a otro con la idea de predicar las misiones populares y se puso en contacto con realidades diversas en multitud de localidades. El texto, en la parte que interesa es:

«Porque aun cuando es cierto que todos los catecismos aprobados por la Iglesia católica enseñan lo mismo, en substancia, también lo es que el método y modo de enseñar de cada uno es muy distinto; de lo que se siguen muchos y muy graves inconvenientes, que apenas pudiera creer si una triste experiencia no hubiera venido a patentizármelos. Y si no, vengamos a la práctica: ¡qué confusión e inconvenientes no se palpan en cada familia! El párroco enseña por el catecismo que ha adoptado; el padre de familia no pocas veces ha sido instruido por otro de diferente método, o que pregunta y responde de diverso modo; la madre, nacida quizá en distinto obispado, naturalmente lo enseña según allí se lo enseñaron; los hijos van a la escuela y el maestro los instruirá también a su modo, pero totalmente diferente; las hijas irán a la enseñanza a 
su respectiva escuela, y allí la maestra las instruirá por el catecismo que ella haya aprendido; y de aquí es indispensable que resulta una confusión casi idéntica a la de Babel, y por consiguiente, o que faltos de criterio tengan menos respeto a nuestras santas creencias, pensando que lo que sólo es diversidad de método, lo es también de dogmas o máximas morales; o que dando al traste con todo, se queden sin instruirse. ¡Qué consecuencias tan fatales!...

Pero no es sólo esto: ya los mayores si han de sufrir un examen para la confesión en tiempo pascual o para contraer matrimonio, y se les pregunta con distintas palabras de las que trae el catecismo por el que fueron instruidos en la niñez, se hallan cortados, no saben responder, quedan avergonzados, y para evitar este lance algo pesado...jay! cuántas veces apelan a ... Dios lo sabe; o cuando menos toman de ahí pretexto para disculpar su ignorancia y negligencia en aprender la doctrina cristiana.

Éstas y otras razones, que por amor a la brevedad omito, espero que las meditarán lo que tiene a su cuidado la enseñanza cristiana de los pueblos y me atrevo a suplicarles humildemente que procuren la total uniformidad de catecismo».

No aparece una reflexión similar en las páginas previas del Catecismo brevísimo, que fueron escritas en Las Palmas por el obispo Buenaventura Codina. Pero el último párrafo reproducido es una llamada de atención a los párrocos, y sobre todo a los obispos, para que no dejaran correr una situación que era al menos problemática, y para la cual la solución no consistía en no hacer nada. Ahora bien, no sé de esfuerzos concretos que siguieran a esta reclamación de Claret, que parece cayó en saco roto.

Hubieron de pasar casi una veintena de años más, para que fuera el propio Claret quien recogiera su clarinazo de alarma, y comenzara a dar pasos para tratar de resolver un problema que personalmente veía preocupante, pero cuya inquietud contrasta con una generalizada apatía, inercia o desinterés. Me gustaría poder decir lo contrario, si hubiera encontrado pistas que descubrieran algún tipo de preocupación; pero no he dado con ellas.

Por los años 1850 a 1857 Claret estuvo ocupado a fondo en su labor como arzobispo de Cuba, razón por la que no pudo detenerse en este tema de la unificación del catecismo; quizá en la isla no encontró el problema de que se emplearan textos diversos, o no he encontrado vestigio alguno que permita pensarlo. Cuando en 1857 regresó a Madrid, y pasó a ocuparse del cargo de confesor real, pudo empezar a retomar el viejo problema que había aireado. En efecto, el 10 de octubre de 1863 escribió a Pío IX solicitando un catecismo único para toda la Iglesia o al menos uno para cada nación; era la postura de recurrir a una autoridad superior, para que, si no 
se lograba la unidad por la vía del convencimiento, se pudiera obtener por decisión superior.

En los meses siguientes, entre octubre y diciembre de 1863, escribió a todos los obispados pidiéndoles directamente dos cosas: $1^{\mathrm{a}}$, información sobre el catecismo o catecismos en uso; y $2^{\mathbf{a}}$, el envío de ejemplares de los mismos, para poder llevara cabo una labor de decantación, contraste y selección. Desconozco qué respuestas obtuvo, pero parece verosímil que, tratándose de un arzobispo, el resto de los obispos respondieran con una información veraz, más allá de la mera cortesía.

De resultas de la recogida de textos y de la información proporcionada, él mismo hizo una selección de los que parecieron mejores o más aceptados; dicha selección estaba constituida por seis catecismos: el de Gaspar Astete, el de Jerónimo de Ripalda ${ }^{30}$, el de Francisco Matheu, que Claret había estudiado de niño, y sobre el que se había basado en los suyos, el Catecismo explicado, que él mismo había escrito, el de Juan Díaz de Baeza ${ }^{31}$, y finalmente el de Novoa $^{32}$. La selección se fundó en los que le parecían mejores. Sus preferencias por el de Matheu no le permitían ser objetivo para contemplar los defectos y las lagunas que el mismo Claret trató de cubrir con su propia obra. No creo que seleccionar su Catecismo explicado haya de ser entendido como un gesto de autosuficiencia, ya que en él había reunido no pocos esfuerzos por perfeccionar el de Matheu; creo que ha de entenderse más como una voluntad de que se valorara un servicio prestado sobre el texto de Matheu, de cuya bondad estaba convenido. Los de Astete y Ripalda gozaban de forma generalizada de una amplia aceptación tradicional, que los convertía en los dos catecismos de mayor implantación en numerosas diócesis españolas; es imposible apreciar qué edición de cada uno envió Claret a Roma, porque para entonces habían tenido lugar las respectivas correcciones de Gabriel Menéndez de Luarca sobre el texto de Astete, y de Juan Antonio de la Riva, sobre el que se consideraba, erróneamente, de

30. Al menos así se tenía en el sentir común hasta hace bien poco, en que he podido demostrar que dicho texto fue escrito por Gaspar Astete, y no por Jerónimo de Ripalda, de manera que, en justicia, hay que denominarlo «segundo Astete»: L. REsines, Astete frente a Ripalda. Dos autores para una obra, en "Teología y Catequesis" n 58 (1996) 89-138.

31. Su título es Catecismo de la doctrina cristiana destinado para la enseñanza y uso de los alumnos del Colegio de Primera clase, Madrid, Imp. de la Sociedad de Operarios del mismo arte, $1848,2^{\mathrm{a}}$ ed.

32. No he podido detectar a qué texto se refiere. Quizá se trate del siguiente: MiguEL NovoA y VARELA, Método fácil y provechoso para disponerse a recibir el sacramento de la penitencia y la Sagrada Comunión, Madrid, 1883. Por la fecha de esta edición, no podría ser, pero quizá ésta sea una edición posterior. Sin embargo, sólo dispongo de la referencia bibliográfica, y no he podido consultar la obra. 
Ripalda; pero, además, en bastantes diócesis corrían ediciones con y sin adiciones, más otras en las que diversas personas habían introducido sus propias modificaciones aleatorias; de ellas unas permanecían y otras se difuminaban con el tiempo, cuando era otra persona (normalmente otro obispo) el encargado de hacer nuevas ediciones y de adoptarlo como texto oficial, o de ratificar su condición de tal.

Con este envío (25 de enero de 1864), Claret pretendió de nuevo el recurso a la vía de la autoridad, de manera que en Roma decidieran cuál era el mejor de todos los elegidos, y que el catecismo designado fuera aceptado como indiscutiblemente mejor por parte de todos los católicos y todas las diócesis («Roma locuta, causa finita»). Sin embargo, las cosas no discurrieron por donde había previsto, y la respuesta de los dicasterios romanos no designó uno con preferencia a los demás. Más bien resultó una especie de varapalo, que dejaba a salvo el prestigio romano, basándose en que todos los catecismos examinados adolecían de algún tipo de defectos, por lo cual no se podía proceder a la asignación de uno en particular como preferible a los otros. En extracto, de la respuesta de Roma, el mismo Claret ofrece una reseña:

«El Padre Santo recibió con agrado los seis Catecismos y los mandó examinar. El examinador sentó las bases o condiciones que debe tener un buen Catecismo, a saber: $1^{\mathrm{a}}$ No debe faltar nada de lo necesario. $2^{\mathrm{a}}$ No debe tener ninguna cosa superflua, a fin de no cargar inúltilmente la memoria. $3^{a}$ Debe ser exacto en la doctrina y en las expresiones, para no enseñar el error. Luego aplicando dichas condiciones a cada uno de los mencionados Catecismos en particular, resultó que ninguno era aceptable, remitiéndonos por escrito el examen, con los defectos que cada uno tenía»33.

Claret no se echó atrás en su intento, sino que, tozudo, emprendió la tarea de elaborar uno que superara las objeciones que se hacían desde Roma a cada uno de los que había presentado. De esta forma, esperaba obtener el beneplácito definitivo, y dar un paso adelante, dejando el asunto zanjado con el nuevo texto:

«En vista de este juicio, que humildemente acatamos, tomamos los seis mencionados Catecismo y los refundimos en uno, aprovechando para su formación lo bueno que aquéllos contenía, y desechando los defectos en ellos notados. Tal es el presente Catecismo.

Mas deseando dar toda la importancia posible a este mismo Catecismo, tuvimos la imponderable dicha, hallándonos en Roma, de po-

33. A.M. ClaRET, «Prólogo» a Catecismo de la doctrina cristiana..., 5. 
nerle en manos de nuestro Santísimo Padre Pío IX el día 23 de noviembre del año 1865 , y le suplicamos humildemente se dignase mandarlo examinar, a fin de tener la seguridad y satisfacción de que la doctrina contenida está enteramente conforme con la doctrina de la Iglesia. Su Santidad tuvo la amabilidad de acceder a nuesta petición: le mandó examinar; en el examen se hicieron algunas observaciones, las que nos han sido remitidas por escrito de orden del mismo Padre Santo, y las hemos aplicado en la presente reimpresión».

$\mathrm{Su}$ insistencia, así como la estratagema de responder a los revisores romanos con sus mismos argumentos, agotaba las oportunidades de éstos para señalar nuevas dificultades, de manera que, incorporada la segunda tanda de correcciones al texto reelaborado, nada le podían argumentar. En cualquier caso, tenía en su mano un catecismo que, si no había sido sancionado oficialmente por Roma, gozaba del prestigio de que había sido revisado por Roma en dos ocasiones sucesivas, y ya no le podían poner nuevas dificultades doctrinales. Era una especie de aceptación romana por vía oficiosa, de manera que podía presentarlo ante cualquier responsable, o ante cualquier auditorio como un catecismo dotado con la aureola de un prestigio ganado a pulso, y que le situaba con ventaja frente a cualquier otro catecismo que quisiera competir con él.

El texto de catecismo que había redactado, por medio de la reelaboración y empleo de elementos procedentes de los seis catecismos elegidos, fue cuidadosamente retenido por Claret, quien no lo dio a la difusión, por deferencia a la presentación previa a Pío IX, en primer lugar, y además, porque esperaba las correcciones que le pudieran hacer al mismo, asegurando así la mayor perfección posible. Llama la atención la frase que redactó y que está transcrita más arriba, según la cual, procedió así «a fin de tener la seguridad y satisfacción de que la doctrina que contiene está enteramente conforme con la doctrina de la Iglesia». Parece deducirse de ella una supuesta «inseguridad» por parte de Claret, que sólo adquiriría su certeza desde la seguridad que pudiera dimanar del revisor romano. Si fuera posible hacer esta lectura, habría que deducir un nivel de escasa preparación teológica, que sería difícil achacar a Claret. De ahí que parezca que el verdadero sentido de las palabras sea el de asignar a Claret el deseo de acomodarse con la mayor fidelidad posible a los gustos y apreciaciones romanas. Es evidente que no se ventilaba ninguna cuestión de ortodoxia, en el sentido estricto de las palabras, sino de preferencias en cuanto al orden, a las materias principales o secundarias, a la forma de expresarse con mayor o menor claridad, $\mathrm{y}$, desde el punto de vista catequético, a la mayor o menor facilidad para que 
una pregunta fuese memorizada, puesto que ésta era toda la preocupación metodológica de la época.

En una palabra, todo eran cuestiones accesorias a la genuina fe, en las que podía prevalecer un criterio o una preferencia sobre otra forma de expresar la misma fe. Y como Claret había «apelado a Roma», era lógico que quisiera acomodarse a los dictados que de Roma provinieran. Cuando le llegaron las sugerencias al catecismo que había presentado personalmente a Pío IX el 23 de noviembre de 1865, las incorporó a su Catecismo de la doctrina cristiana, y con este título lo editó. Según mis noticias, primero lo editó en Madrid, en edición castellana en 1866, y al año siguiente, 1867, hizo lo propio en Barcelona, en edición catalana. A pesar de que tuvo numerosas ediciones, este catecismo, pulido una y otra vez, con el objetivo de que llegara a ser el texto único que resolviera los problemas de la multiplicidad de catecismos, al menos en España, y que substituyera a los tradicionales de cada diócesis, no consiguió su objetivo, y fue uno más en la ya amplia oferta de catecismos.

El 8 de diciembre 1869 tuvo lugar la apertura del Concilio Vaticano I, y una de las cuestiones que se debatieron fue la de la propuesta de un catecismo único para toda la Iglesia. Es posible que influyeran en el ánimo de Pío IX las gestiones previas y reiteradas de Claret con vistas a España. Además, en el aula conciliar se debatieron otras razones a propósito de esta cuestión, como la rapidez de comunicaciones y desplazamientos de población, el número de emigrantes que en algunas diócesis suponía un serio problema, porque los lugares de procedencia eran bien distintos y la formación religiosa de cada uno tenía unos matices diferenciadores. Sin embargo, la cuestión no resultó tan trivial como podría pensarse, porque también subió a la palestra la voz de los que defendían el derecho de cada obispo a arbitrar los medios que estimara oportunos para la educación de la fe en su diócesis, sin tener que plegarse a dictados que vinieran de fuera. Las discusiones conciliares llegaron incluso a molestar a algunos miembros del episcopado que mantenían una postura previa de aceptación obediencial de todo cuanto procediera de Roma, como si ello fuera suficiente para garantizar su calidad. Para algunos obispos partidarios de tomar sus propias decisiones y de mantener la autonomía episcopal, la propuesta de un catecismo único despertaba suspicacias y recelos, así como la sensación de una ingerencia no deseada.

De parte del episcopado español tomaron la palabra los obispos Miguel Payá, de Cuenca, José María Urquinaona, de Canarias, Manuel García Gil, de Zaragoza, Antolín Monescillo, de Jaén, y Esteban José Pérez Fernández, obispo de Málaga. El esquema «de confectione et usu unius parvi catechis- 
mi pro universa Ecclesia» se distribuyó el 14 de enero de 1870; y las intervenciones de los obispos españoles tuvieron lugar entre el 15 y el 22 de febrero de ese mismo año, en el curso de las Congregaciones Generales. Todos los obispos españoles que tomaron la palabra sobre el tema se pronunciaron en el sentido de la aceptación incondicional de lo que viniera de Roma, así como en urgir el ritmo de las discusiones frente al escaso avance, debido a las voces contrarias.

Llama la atención que Claret, tan interesado en el tema, sin duda más que otros, no tomara la palabra en este asunto. Sin embargo, no es posible afirmar que estuviera callado, puesto que, fuera del aula conciliar, se dirigió en una charla a los obispos españoles, para hacerles tomar conciencia de la situación. Su intervención tuvo lugar el 11 o el 17 de febrero de 1870, en los días previos a la discusión conciliar. Se conserva un apunte de lo que pudo ser tal conferencia, y que es revelador de los acentos que Claret expresó al episcopado español:

«Se trata del esquema sobre la formación del pequeño Catecismo. Mucho me place la idea y no dudo que será de grande gloria de Dios y bien de las almas $\mathrm{y}$, por lo mismo, todos debemos apresurarnos a dar nuestro voto.

Tres razones en que me apoyo.

$1^{a}$ Es la voluntad de nuestro Santísimo Padre; al efecto nos ha entregado el esquema. Es ésta para mí una razón tan poderosa que me convence plenamente.

$2^{\mathrm{a}}$ En alguna manera el proyectar la formación del pequeño Catecismo es imitar a los santos apóstoles, quienes en Jerusalén, antes de diseminarse por el mundo a predicar el santo Evangelio, compusieron u ordenaron el Credo a fin de enseñar todos una misma doctrina. Ya que nosotros nos hallamos reunidos en Roma, en este santo concilio Vaticano, justo será que antes de separarnos por el mundo a las correspondientes diócesis, se forme el pequeño Catecismo.

$3^{\mathrm{a}}$ Algunos Padres orientales lo han pedido, y así ellos y nosotros tendremos la satisfacción de saber que ellos y nosotros enseñamos todos la misma doctrina.

He hablado de las razones, ahora diré que es fácil el componer este pequeño Catecismo, pues se ha de componer únicamente de las cosas necesarias, de necesidad de medio y de necesidad de precepto. V. gr.: Quién nos ha criado, para qué fin; Unidad de Dios, Trinidad de personas, Redención, premio de los buenos y castigo de los malos, Padre nuestro y Ave María, Credo, Mandamiento de la Ley de Dios, Sacramentos.

Este pequeño Catecismo será para los niños y rústicos, y al mismo tiempo se compondrá otro Catecismo que será para los niños que van a las escuelas. 
Este Catecismo será nacional o provincial y lo pondrán los obispos en sus Sínodos. Este segundo Catecismo podrán componerlo sobre las bases del primero y extenderse según la necesidad de cada país.

Con este segundo Catecismo, podrán los párrocos instruir a los niños y rústicos sobre el modo de recibir los Sacramentos cuando sea menester.

Sobre la unidad de Catecismo en España.

En Roma no es admitido ninguno de los que en el día se enseñan.

Dijeron que admiraban mucho que tuvieran tan abandonada una cosa tan necesaria.

Yo por esto compuse el presente.

Fue aprobado por el Ordinario y por la Junta.

Junta de Instrucción Pública.

Fue mandado de texto para la segunda enseñanza.

No obstante todas estas garantías, con tal que se haga general, renuncio a cuanto he hecho y deseo que se forme una comisión por todos los obispos españoles, y que esta comisión examine nuevamente mi Catecismo, que añada o quite lo que tenga por conveniente, o que haga otro nuevo, a gusto de todos» 34 .

La nota anterior sugiere algunas observaciones. En primer lugar, en las razones que le movieron a solicitar su voto a los obispos españoles, es patente la postura de obediencia sumisa a cuanto viniera expresamente de Roma, como si la labor de un concilio ecuménico consistiera en aprobar por unanimidad las propuestas previas. Es lógico que, con tal criterio, Claret llevara a mal las discusiones y las razones de quienes se oponían al proyecto de catecismo universal, en la misma medida en que también vio mal, e incluso con cierto escándalo las razones que se adujeron en la discusión del tema de la infalibilidad pontificia ${ }^{35}$. El que unas cuestiones se sometan a discusión quiere decir que es el momento del debate y del discernimiento, y no es posible identificarlo con el simple asentimiento, como Claret deseaba. En segundo lugar, parece ingenuo que Claret adujera razones sobre la composición del credo por parte de los apóstoles, como si de un hecho histórico se tratara, cuando era sabido que no fue así, y que la asignación del credo a los apóstoles no pasa de ser una mera conjetura, además tardía. En

34. J. M. VIÑAS, o. c., 506-509.

35. 29 de mayo de 1870: en carta a uno de sus colaboradores, P. Xifré, dice: «Cuando oí los despropósitos y aun las blasfemias y herejías que se decían [en oposición a la infalibilidad pontificia] sentí dentro de mí tal indignación y celo, que me subió la sangre a la cabeza y me causó una ligera conmoción cerebral», en J. M. VIÑAS, o. c., 58. 
términos parecidos se expresa en la tercera razón, con el deseo de que orientales y occidentales coincidan en la misma fe, precisamente por el empleo del mismo catecismo.

En los apuntes que hizo con relación al tema en España, aparece clara su experiencia anterior. De ella tomó el dato que posiblemente pudo causar una cierta conmoción en gran parte del episcopado de que ninguno de los catecismos en uso era admitido por Roma, así como la delicada acusación de desidia en esta cuestión. Por ello, sin vanagloria, presentó su Catecismo de la doctrina cristiana, corregido en Roma, y aprobado también, según los requisitos usuales, por la censura madrileña, y aceptado por la Junta de Instrucción Pública como libro de texto. Claret presentó su escrito como un trabajo que había realizado, adelantando etapas en orden a conseguir la unificación para España. A la vez, con una honradez digna de todo encomio, lo puso a disposición de los obispos, para que fueran éstos, en comisión, los que lo examinaran, añadieran o quitaran lo que fuera conveniente, o incluso que lo relegaran como inservible, si el criterio que se pudiera aceptar fuera el de redactar otro. No existe el más mínimo rastro de imposición o de haber querido cobrar una ventaja por el hecho de haberse adelantado al resto de los obispos dando pasos en esa dirección. Ofreció su trabajo y antepuso la decisión colectiva a cualquier tipo de prestigio o gloria personal.

Es sabido que el Concilio Vaticano I vio forzada su conclusión con la declaración de guerra franco-prusiana. Y con ello, el esquema «de parvo catechismo», quedó aprobado, pero inoperante, por no haber sido promulgado. Resulta sorprendente que el interés manifestado en el aula conciliar por algunos obispos españoles (y parece que refrendado por la mayoría de los restantes), concluido el concilio, no pasara a la acción. Da la sensación de que, defraudados por la interrupción conciliar inesperada, no fueron capaces de reaccionar, y como no llegaba la solución desde Roma, tampoco encontraron los mecanismos para plantear el problema y tratar de solucionarlo. $\mathrm{Ni}$ siquiera se llevó a cabo la propuesta de Claret de crear una comisión (amplia o restringida) al efecto, propuesta que resultaba concreta y práctica. Y la aparente unanimidad de voluntades se esfumó con el tiempo ${ }^{36}$.

36. En el Tercer Congreso Católico (Sevilla, 1892) aparece una tibia propuesta en las conclusiones: «Es muy digno de elogio el celo desplegado por personas de piedad, corporaciones y casas editoriales para facilitar la adquisición del catecismo, publicando en hojas sueltas este precioso libro, para distribuirlas entre los fieles durante la explicación parroquial y las conferencias catequísticas. A fin de favorecer más esta propaganda sería muy conveniente la unificación que de los catecismos elementales pueda hacerse, mientras no tenga lugar la publicación del Catecismo decretada por el Concilio Vaticano»: Crónica del 
Claret murió el mismo año 1870. No pudo proseguir con este empeño. Su Catecismo de la doctrina cristiana, que había escrito y propuesto para que sirviera de texto único tuvo una cierta aceptación, a juzgar por sus ediciones, pero fue uno más en la panoplia de catecismos, sin que exista la certeza de que en ninguna diócesis se tuviera en cuenta de forma oficial, hasta el punto de adoptarlo como texto que substituyera al que estuviera hasta entonces en uso. Sin embargo, este olvido no fue tal para los claretianos, que lo continuaron usando como el más precioso legado de su fundador. Hasta el punto de que en 1912 difundieron por todas las diócesis una propuesta de que se substituyera el texto tradicional respectivo por el Catecismo de la doctrina cristiana, que pasaría a ser texto oficial diocesano; tal substitución correría a cargo de los misioneros claretianos y abarcaría a parroquias y escuelas ${ }^{37}$.

Analizando el Catecismo de la doctrina cristiana, en el «prólogo» aparecen algunas indicaciones dignas de consideración. La primera, extrañísima, es una larga cita en pro de la unidad el catecismo que Claret toma «del Emmo. Sr. Cardenal Caprara el día 30 de Marzo del año 1806». No ofrece más detalles. Cualquiera que no esté suficientemente documentado podría pensar que se trata de alguna reflexión efectuada por Caprara sobre este tema, y que Claret emplea benévolamente, incluso con la honestidad de mencionar su procedencia. Ahora bien, conociendo el origen de la cita, las cosas cambian mucho. Porque la referencia en cuestión forma parte de la aprobación que el cardenal Juan Bautista Caprara, nuncio de Pío VII en París, incluyó en el Catecismo para el uso de todas las Iglesias del Imperio francés, aprobado por el cardenal Caprara, legado de la Santa Sede y mandado publicar por el Emperador Napoleón. Es de sobra conocido que en el mismo, una lección sobre el cuarto mandamiento, pretendía imponer y exigir una obediencia religiosa al emperador, en nombre de Dios. También es conocido que el nuncio Caprara, débil y acomodaticio, cedió a las presiones de Napoleón, para que el texto fuera publicado con la máxima autoridad posible. Y también resulta conocido el profundo disgusto que provocó la obra a Pío VII al enterarse del contenido manipulador que tal catecismo incluía. Napoleón se apoyó en el artículo 39 de la ley orgánica de 8 de abril

Tercer Congreso Catequístico Nacional Español. Discursos pronunciados en las sesiones públicas y reseña de las memorias y trabajos presentados en las secciones de dicha Asamblea, celebrada en Sevilla en octubre de 1892, Sevilla, Tip. El Obrero de Nazaret, 1893, Conclusiones, sección II, punto II, $2^{\circ}$.

37. A. IVARS, La enseñanza catequística y el "Catecismo del P. Pedro Vives», en "Archivo Ibero Americano" 18 (1922) 94-95. 
de 1802 (o su equivalente, 18 germinal del año X), que disponía: «Il n’y aura qu'une liturgie et qu'un catéchisme en France». En consonancia con tal claudicación religiosa frente a la imposición política, Napoleón encargó la redacción de un catecismo, ciertamente único para toda Francia, que era un instrumento de intervención política con ribetes religiosos.

No es fácil que Claret desconociera estos detalles, o al menos lo substancial de ellos. Pero vio la oportunidad de una referencia que favorecía sus deseos unificadores y no dudó en ponerla al frente de su prólogo ${ }^{38}$. Precisamente por el contexto en que surgió y estuvo envuelta, tal cita no era la más adecuada ni la más ejemplar de cómo se podía conseguir la unidad nacional en torno a un catecismo. Pero Claret no tuvo demasiados escrúpulos en utilizarla, extrayéndola de su contexto, porque servía a sus propósitos.

A continuación Claret relata el proceso de recogida de textos e información en todas las diócesis, la selección de los mismos, el envío a Roma, y la respuesta extractada que le enviaron, la redacción de un texto refundido con elementos escogidos de los catecismos seleccionados, la entrega del mismo a Pío IX, las correcciones últimas que le indicaron, y, finalmente, la redacción definitiva del texto, que ponía a disposición de todos, como propuesta de solución frente a la multiplicidad de catecismos.

Las «advertencias» que siguen al «prólogo» tienen un valor particular para el uso del catecismo, especialmente las que figuran en primer y tercer lugar. La primera advertencia indica que algunas preguntas disponen de un asterisco, y se destinan a los que tienen poco tiempo o poca capacidad; y que las preguntas que tienen dos asteriscos son las más importantes, y por tanto, en las que hay que poner mayor atención. Esto, que podría ser un avance pedagógico notable, es en realidad un retroceso en el tiempo, porque señala con dos asteriscos las preguntas que tiempo atrás había publicado con el doble título de Catecisme menor que per la ensenyansa del noys y

38. El texto de la cita es: «A todos es notorio que nuestros mayores pensaron sabiamente que se debía observar una regla constante y común en enseñar y aprender la doctrina cristiana, la cual acarrearía grandísimo provecho a la acertada instrucción del pueblo cristiano, y particularmente de los niños. Porque, ¿qué cosa puede pensarse más oportuna que semejante uniformidad, ni qué cosa más útil puede darse que ésta? En efecto, por medio de ella, todos los que han sido llamados a la unidad de la fe, siendo de un mismo sentir y diciendo una misma cosa, serán con más facilidad perfectos en un mismo ánimo y en un mismo parecer. / Los Sumos Pontífices, por otra parte, en virtud de la solicitud pastoral que tienen de todas las iglesias, han exhortado muchas veces y recomendado con el mayor encarecimiento que observasen todos el mismo e idéntico modo de proponer y enseñar la doctrina cristiana. / Así como una es la fe, del mismo modo sea también una y común la forma y método de proponer la misma fe e instruir al pueblo». 
noyas luego que saben parlar ha escrito lo R. D., y han adoptat las societats de la Doctrina cristiana del Principat de Catalunya, Barcelona, Her. de Vda. de Plá, 1847, o de Primer catecismo que se enseñará a los niños desde que empiecen a hablar. Es cierto que existe alguna ligera modificación entre la presentación de 1847 y la que aparecía en 1866, pero substancialmente son las mismas. Claret reaprovechó sus propios materiales, acaso porque la selección que hizo entonces le seguía pareciendo oportuna. Además de señalarlas con dos asteriscos, agrupó y reprodujo juntas todas estas preguntas en el mismo texto comentado, con la diferencia de que el título con que lo había publicado en 1847 lo modificó en el Catecismo de la doctrina cristiana en «Preguntas escogidas que se han de hacer a los niños de poca edad $\mathrm{y}$ a los adultos ignorantes».

La tercera advertencia remite a la consulta de la obra que él había escrito, El Colegial instruido, tomo $2^{\circ}$, página 515 , donde expresa el método más adecuado para la práctica de la catequesis ${ }^{39}$. Acompaña a las «advertencias» una breve «nota» que dice, corroborando lo anterior: «Este Catecismo aprenderán de memoria los niños y niñas; mas las personas adultas que recuerdan el que aprendieron, leerán éste repetidas veces con reflexión».

Sigue el «Plan e índice de la doctrina», que consiste en mantener el mismo esquema que Claret mantuvo en todos sus catecismos anteriores, que procedía de Matheu directamente, e indirectamente de Ledesma; Claret lo había empleado en el Compendio y en el Catecismo explicado. Y en esta ocasión mantuvo la modificación que ya entonces había introducido respecto de Matheu, en el sentido de dividir las obras en dos categorías, las malas o pecados, y las buenas, o sacramentos y virtudes.

Este «Plan e índice de la doctrina» incluye y a la vez da paso a un nuevo apartado que responde al título de «Texto de la doctrina cristiana». En el mismo, Claret desplazó, para su presentación a Roma, todos los formularios de las oraciones; hasta entonces, tales formularios aparecían en los catecismos de Claret (y en el de Matheu) integrados armónicamente en el texto; ahora formó con ellos un apartado inicial que los agrupaba. Y el «Plan e índice de la doctrina» remite en doble columna al lugar en que consta cada formulario en el «Texto de la doctrina cristiana»y, después, en la explica-

39. Consultada la obra, el método con el que hacer progresos en la catequesis se reduce a unas indicaciones prácticas sobre cómo sentar a los niños, cómo comenzar la catequesis, cómo hacer las preguntas a los niños y éstos entre sí, hasta conseguir que las memoricen, $y$, finalmente, hacer alguna comprobación para que, una vez que han memorizado el catecismo, se compruebe si lo entienden o no. Como se ve, el método es fundamentalmente práctico, pero no aporta reflexión alguna que fuera más allá del aprendizaje de memoria. 
ción, a base de preguntas y respuestas. En éstas, cuando tiene que referirse a un formulario, no lo repite sino que simplemente remite a la página correspondiente de este apartado previo. El «Texto de la doctrina cristiana» resulta una novedad respecto a los anteriores catecismos de Claret ${ }^{40}$. Su realización pudo ser debida a exigencias de Roma, o a imitar la mayor parte de los catecismos, que agrupaban las oraciones y formularios en un apartado inicial.

Al fijar la atención en las preguntas y respuestas, que constituyen el grueso del Catecismo de la doctrina cristiana, hay que considerar diversos aspectos:

1) El título que preside toda la parte interrogativa es: «Breve explicación de la doctrina cristiana». Las preguntas y respuestas, concatenadas, suministran una explicación progresiva; de ahí que no resulte un título abusivo en absoluto. Pero no se trata de una «explicación» en el sentido en que la había empleado en el Catecismo explicado, donde junto a las preguntas y respuestas, aparecía una exposición amplia y razonada, vinculada a la lámina correspondiente, y a las preguntas y respuestas que seguían a continuación. En este caso no es así, y toda la «explicación» consiste en enlazar una pregunta con otra, para que su discurrir engarzado haga avanzar el conocimiento de la doctrina, haciendo que una pregunta aclare o amplíe lo insinuado en la pregunta anterior; o que avance la materia con nuevas cuestiones. Toda la «explicación», pues, consiste en preguntas y respuestas. Con ello, Claret se amolda al modelo más generalizado de catecismo. No olvidemos que de los que había seleccionado y presentado en Roma, los de Astete (primero y segundo, llamado de Ripalda), el de Matheu, y el de Baeza consistían exclusivamente en preguntas y respuestas, y que el suyo, incluía preguntas y respuestas, más de una amplia exposición no interrogativa, sino discursiva ${ }^{41}$.

40. En el «Texto de la doctrina cristiana» figuran, por este orden: señal de la cruz, credo, padrenuestro, avemaría, salve, mandamientos de Dios, mandamientos de la Iglesia, enemigos del alma, pecados capitales, sacramentos, virtudes teologales, virtudes cardinales, dones del Espíritu Santo, frutos del Espíritu Santo, bienaventuranzas, obras de misericordia, potencias del alma, sentidos corporales, novísimos, confesión general, acto de contrición, gloria (bilingüe, latín y castellano) y ave maría purísima.

41. En las preguntas que llevan por respuesta un «sí», o un «no», aunque se complete después con otra afirmación, Claret sugiere lo siguiente como norma de urbanidad: «Sí... es una respuesta demasiadamente seca; por tanto, se podrá decir: Sí, padre; sí, señor; o sí, señora». La misma advertencia, más completa, ya había aparecido en el Primer catecismo que se enseñará a los niños desde que empiezan a hablar hasta los siete años, incluido en la $15^{\mathrm{a}}$ ed. del Catecismo explicado, Barcelona, Lib., Religiosa, 1862, 11: «Sí... es una expresión 
2) En las preguntas y respuestas sigue el esquema señalado para la obra, el de sus anteriores catecismos Compendio... y Catecismo explicado. Es el que aparecía en el «Plan e índice» aludido.

3) Por tanto, sigue fundamentalmente el texto de Matheu. Vuelve a aparecer la predilección de Claret por el que había sido texto de su infancia, y en el que había cristalizado como creyente. Por eso mismo es el que siguió en los catecismos anteriormente referidos, aunque lo hubiera retocado y ampliado en el Compendio, y todavía lo ampliara algo más en el Catecismo explicado. Es obligado afirmar que, en realidad, de los seis textos seleccionados y enviados a Roma, es más cierto decir que son cinco, porque Matheu y Claret coinciden fundamentalmente. $\mathrm{Y}$ a poco observadores que fueran los examinadores romanos tuvieron que caer en la cuenta del subrayado que Claret incluía presentando dos textos, de los que uno era la cimentación indispensable para el otro.

4) Según los criterios remitidos desde Roma, Claret hizo una refundición. Es la que constituye el conjunto de preguntas y respuestas de este catecismo con pretensiones de perfección, para aspirar a que fuera tenido en cuenta como texto único. El conjunto de preguntas y respuestas resulta un conglomerado final, fruto de muchos retoques, y depósito al que van a parar las aportaciones de preguntas que proceden de todos los catecismos que tuvo sobre la mesa, y que manejó discrecionalmente. Sería enormemente fatigoso ir, pregunta por pregunta, señalando su procedencia respectiva. Pero es posible hacer unas apreciaciones globales:

- aparece como substrato básico la amalgama procedente de MatheuClaret que se encuentra en el Catecismo explicado. Además hay algunas preguntas que procedían del Primer catecismo que se enseñará a los niños desde que empiezan a hablar hasta los siete años, y que también se encuentran en el Catecismo explicado.

- aparecen algunos añadidos tomados claramente de Astete (aunque hayan sido retocados en su redacción). Ya había algunos de Astete en el Catecismo explicado, pero ahora son más en cantidad, y se perciben incluso con mayor claridad.

- aparecen otros añadidos tomados del segundo Astete (llamado tradicionalmente de Ripalda), que a veces han sido retocados. Como Claret no

demasiadamente seca, y así se dirá: Sí, mamá; sí, papá, cuando el niño es pequeñito; pero cuando ya será mayorcito, a su padre y a su madre les responderá: Sí, señor; sí, señora. Tanto si es pequeño el niño como grandecito, siempre que será preguntado por el Sacerdote responderá: sí, padre, o sí, señor. Al maestro responderá: Sí, señor. A la religiosa, maestra, abuela, tía, etc..., sí, señora». 
se paró a considerar si se trataba del texto genuino del segundo Astete, o de adiciones al mismo (efectuadas por Juan Antonio de la Riva), incluyó indiscriminadamente unas y otras, según le venían bien.

- es más difícil precisar las influencias que provienen de Baeza, que me parece apreciar que son menos en número y están más dispersas.

- el no haber podido consultar el catecismo de Novoa no me permite hacer un juicio sobre las aportaciones que procedieran de él. Pero, por eliminación, quitando las que ya estaban en el bloque Matheu-Claret, y las que provienen de Astete y del segundo Astete, son probablemente escasas en número, como ocurría con las de Baeza.

5) Por mantener la fidelidad al núcleo primitivo de Matheu, al final de la explicación del credo sigue la explicación de los artículos de la fe. El credo estaba tradicionalmente dividido en los doce artículos o frases, cuya autoría erróneamente se asignaba a los mismos apóstoles; los artículos de la fe estaban constituidos por catorce afirmaciones o artículos, agrupados en dos series, correspondientes a la divinidad, y a la humanidad de Jesucristo. En realidad, las dos maneras trataban de presentar lo fundamental de la fe, pero al no coincidir, había matices en una lista que no estaban en la otra. Matheu mantuvo ambas, con el desajuste pedagógico de volver, en la presentación de los artículos de la fe, sobre temas que ya habían salido al presentar la explicación sobre el credo. Claret se mantuvo fiel a este proyecto, y en ninguno de sus catecismos hizo intento alguno de armonizar ambas series de explicaciones; se conformó con poner una explicación a continuación de la otra. En el Catecismo de la doctrina cristiana hizo lo mismo. Y como la presentación de los artículos de la fe era común en España, y bastante menos conocida fuera de ella, el único ajuste que realizó Claret fue substituir la palabra «Artículos», a modo de título, por este otro circunloquio: «De Dios y de los misterios de la Santísima Trinidad, Encarnación y Redención en particular». Así era más fácil no encontrar dificultades en la censura romana; e insistir en algunos aspectos determinados no podría parecerles mal a los revisores. Se mantenía, no obstante, el error pedagógico de una repetición innecesaria y dispuesta con escasa lógica.

6) Al realizar la refundición, Claret mejoró la redacción de algunas preguntas. En sus catecismos anteriores, Claret se atuvo únicamente a lo que encontró en Matheu, que le parecía la expresión más acertada y feliz, acaso porque, aprendida desde niño, la había integrado en sus conocimientos; ya de mayor, no apreciaba dificultad alguna, o al menos posibilidad de mejora. Con las indicaciones venidas desde Roma, reconsideró que la expresión 
de ciertas preguntas podía mejorar sensiblemente, y con ello ganar en claridad, y en facilidad de ser aprendidas de memoria.

7) Suprime algunas partes que aparecían en sus anteriores catecismos. Probablemente el criterio expresado desde Roma según el cual el catecismo ideal no debería tener nada superfluo o innecesario llevó a Claret a suprimir unas cuantas preguntas. No me refiero a preguntas aisladas, que podrían eliminarse, o ser substituịdas ventajosamente por otras más exactas o más claras; me refiero a preguntas agrupadas en torno a una misma materia. Así, suprimió las preguntas que explicaban al detalle las afirmaciones de la Salve, contentándose con su recitación; lo mismo ocurrió con las preguntas que iban desgranando, una a una, las bienaventuranzas; lo mismo ocurrió con las preguntas sobre cada uno de los frutos del Espíritu Santo; y también con las preguntas que comentaban las obras de misericordia.

8) Amplía algunos temas. Podría ponerse como ejemplo más evidente el del sacramento del orden, que, desde Matheu disponía de dos preguntas (cuál es el nombre, y qué gracia proporciona); en la redacción del Catecismo de la doctrina cristiana se mantienen las dos preguntas anteriores, al comienzo, pero a ellas se añaden otras once preguntas más sobre la dignidad de los sacerdotes, la institución del sacramento por Cristo, el respeto debido, el carácter que imprime,...

9) Finalmente, las principales novedades que se observan como datos hasta ahora no presentes en los catecismos anteriores de Claret son las que reseño a continuación. Hay que hacer una indicación en el sentido de que, en la mayor parte de las ocasiones, estas novedades están representadas por unas cuantas preguntas concatenadas. Son las menos las ocasiones en que aparecen en una única pregunta. Por otro lado, está fuera de lugar pretender ver aquí una reseña de todas las preguntas estrictamente nuevas, sino más bien las ideas o aportaciones que anteriormente apenas tenían cabida en los catecismos de Claret. He aquí la lista de las principales novedades:

- explicación simbólica de la cruz

- cambia la expresión «buenas obras» por «recibir» los sacramentos ( $4^{\mathrm{a}}$ parte).

- obligación de los padres, párrocos y maestros de enseñar la doctrina cristiana.

- clases de fe: divina y humana.

- doctrina sobre los ángeles.

- creación del hombre.

- conservación del mundo; existencia de males y desigualdades. 
- naturalezas, personas, entendimientos, voluntades y memorias en Cristo.

- existencia de libertad en el hombre.

- clases de oración: mental y vocal.

- oración a los ángeles y a los santos.

- frutos que se siguen de la observancia de los mandamientos.

- no pecan los soldados o ministros de la justicia cuando matan.

- obligación del gobierno de sostener al culto y sus ministros.

- división del pecado en original y personal.

- número de pasiones que afectan al hombre: once en total.

- Dios no permite la tentación mayor que la gracia.

- clases de gracia: santificante y actual; su necesidad.

- ampliación en el sacramento del orden.

Todas estas pinceladas muestran por dónde discurrió la refundición llevada a cabo por Claret. Su deseo de perfeccionamiento, a la búsqueda del catecismo ideal, supuso una labor de recopilación, corrección de estilo, propuesta de nueva redacción, eliminación de algunos detalles secundarios,... Se adivina fácilmente que todo ese trabajo le ocupara un tiempo notable, porque no se trató simplemente de escribir de nuevo, sino de cotejar, comparar, elegir y decidir la forma mejor. Sin embargo, todo ello lo hizo a partir de un edificio ya construido: no partió de cero, sino que reformó lo que había redactado antes en el Catecismo explicado, en el que permanecía todo el substrato de lo redactado por Matheu, a modo de cimiento. Es posible concluir, por tanto, que lo que Claret hizo en este catecismo fue llevar a cabo una importante reforma secundaria sobre lo construido antes, pero el edificio antiguo es perfectamente reconocible, pese a los retoques y cambios accesorios que se incorporaron, que no llegaron a afectar a lo fundamental.

Por último, es obligado dejar constancia de que, muerto ya Claret, alguna mano cuyo nombre no consta, llevó a cabo una trasformación importante: el texto de catecismo más amplio de Claret, el Catecismo explicado, se continuó editando. Pero sin aviso indicador alguno, se mantuvieron las láminas (que ya habían substituido a las originales de Claret); se mantuvo la parte expositiva de explicaciones amplias; pero las preguntas y respuestas, que eran las que figuraban en el Compendio, más algunas adiciones, fueron cambiadas por las que aparecían en el Catecismo de la doctrina cristiana, distribuyéndolas con arreglo a las lecciones en que estaba dividido el libro. El «prólogo» también fue modificado, conservando algunos párrafos 
que procedían de Claret, entremezclados con otros que él no escribió; y en dicho prólogo se suprimió toda referencia al catecismo de Francisco Matheu y Smandía, por el que Claret siempre había mostrado su predilección y presentado con satisfacción como el mejor, aunque él lo retocara. El anónimo corrector estimó que el Catecismo de la doctrina cristiana era, con mucho, el mejor, y por tanto sobraban referencias a cualquier otro catecismo distinto de éste. Figura también íntegra la «advertencia» que Claret puso al frente de su Catecismo de la doctrina cristiana, con un párrafo espurio que indicaba que se añadía, también, el Primer catecismo que se enseñará a los niños desde que empiecen a hablar ${ }^{42}$.

42. Esto sucede, al menos, en la edición de Barcelona, Librería Religiosa, 1875, que carece de indicación sobre el ordinal de la edición. Me figuro que también habrá sucedido en otras ediciones más, que no he podido consultar, después de 1870 y anteriores a ésta de 1875, y, sobre todo, posteriores a esa fecha. Así sucede, también en la edición de Barcelona, Imp. y Librería de Montserrat, 1905, como prueba de lo anteriormente apuntado. 